\title{
Entre a arte de comunicar e ofício de ser acessivel: estudo sobre os recursos de acessibilidade para visitantes com deficiência visual no site de um museu de Belo Horizonte ${ }^{1}$
}

Between the art of communicating and the craft of being accessible: a study of accessibility features for visually impaired visitors on a Belo Horizonte Museum website

https://doi.org/10.1590/1982-02672020v28e12

\author{
MÍRIAM CÉLIA RODRIGUES SILVA² \\ https:/ / orcid.org/0000-0002-0 $127-0630$ \\ Universidade do Estado de Minas Gerais / Belo Horizonte, MG, Brasil
}

\section{JOSÉ DE SOUSA MIGUEL LOPES³}

https: / / orcid.org/0000-0002-0015-0100

Universidade do Estado de Minas Gerais / Belo Horizonte, MG, Brasil

RESUMO: Esta investigação tem como propósito analisar como se configura a acessibilidade nos sites dos museus. Para a realização do estudo, oito participantes com deficiência visual foram convidados a visitar o site do Museu de Artes e Ofícios (MAO) e, de acordo com suas experiências, a responder um questionário sobre as condições e os recursos oferecidos pela página. $\bigcirc$ questionário foi disponibilizado em uma plataforma on-line e teve o link enviado por e-mail. A investigação contou também com a utilização de uma ferramenta automática que avalia a acessibilidade de sites. Todos os instrumentos empregados na pesquisa foram inspirados nas Diretrizes de Acessibilidade da Web, orientações elaboradas por pesquisadores do Consórcio W3C que visam a tornar os conteúdos das páginas da internet mais acessíveis. Os sites podem contribuir para a projeção da instituição e de seu acervo e ser um elemento que estimule, oriente ou complemente uma visita, desde que viabilize o processo de comunicação através do oferecimento de recursos adequados às habilidades e capacidades dos indivíduos.

\begin{abstract}
1. O presente artigo é resultado de uma dissertação de mestrado intitulada A acessibilidade nos sites dos museus e sua influência na dimensão educativa das instituições: um estudo sob a perspectiva dos visitantes com deficiência visual.

2. Mestre em Educação pela Universidade do Estado de Minas Gerais (UEMG). Graduada em Museologia pela Universidade Federal de Minas Gerais (UFMG). E-mail: $<$ miriamkayte@hotmail. com>.
\end{abstract}

3. Pós-doutor pela Universidade de Lisboa, doutor em História e Filosofia da Educação pela Pontifícia Universidade Católica de São Paulo, mestre em Educação pela UFMG e graduado em Pedagogia pela mesma universidade (2013). Atualmente é professor no mestrado em Educação na UEMG. E-mail: $<$ miguel-lopes@uol.com.br>. 
No que tange à análise da acessibilidade do site do $M A O$, a investigação demonstrou que, apesar de alguns elementos estarem de acordo com as recomendações de acessibilidade, a página ainda não supre as expectativas com relação a outros aspectos. Por fim, não foram encontrados textos na página que remetam à acessibilidade ou descrevam os recursos para ampliar o acesso, o que pode indicar que o tema não é uma pauta do site do museu.

Palavras-chave: Acessibilidade. Museus. Sites. Comunicação. Internet.

Abstract: This research aims to analyze how accessibility is configured in museums websites. To perform this study, eight subjects with visual impairment were invited to visit the website of Museu de Artes e Ofícios-MAO and according to their experience, they were asked to answer a questionnaire about the conditions and resources offered by the web page. The quiz was available on an online platform and its link was sent via e-mail. The research also counted on the use of an automatic tool that evaluates the accessibility of websites. All tools were inspired by the Guidelines of Web Accessibility, guidelines elaborated by Consortium W3C and aiming to make web pages contents more accessible. Websites can contribute to the projection of the institution and its collection, to be an element that stimulates, orientates or completes a visit as long as it enables the communication process through the provision of adequate resources to the abilities and capacity of individuals. Regarding the accessibility analysis of the MAO website, the research has shown that although some elements are in line with accessibility recommendations, the webpage still does not meet expectations regarding other aspects. Finally, there were no texts found on the web page that refer to accessibility or describe the resources to expand access, which may indicate that this thematic is not a main concern of the Museum website.

Key-words: Accessibility. Museums. Sites. Communication. Internet. 
As instituições museológicas cresceram exponencialmente em número e tipologia a partir da década de 1990, período em que houve ampliação da rede mundial de computadores e propagação dos sites dos espaços museais. Em um cenário caracterizado por debates, expectativas e inquietações, a internet se constituiu como uma importante ferramenta de comunicação, criando perspectivas para apresentação do acervo e abrangência de um público mais amplo e variado. ${ }^{4}$ De fato, a difusão dos museus na rede pode romper com algumas barreiras, possibilitando que conteúdos sobre coleções ou informações a respeito de instituições de determinado país circulem dentro da região e em várias nações. Tal fato propicia, por exemplo, que uma pessoa de nacionalidade espanhola, ao acessar o site do Museu Picasso, obtenha informações prévias do local que pretende visitar: saiba, desse modo, que atualmente a instituição abriga a exposição fotográfica que retrata alguns momentos da vida de Picasso registrados pelo amigo e fotógrafo Lucien Clergue; esteja ciente de que, aos domingos, o museu oferece visita guiada em três horários, sendo realizadas em castelhano, catalão e inglês; e seja informado de que a partir de determinado valor poderá acompanhar detalhes das obras por meio de um audioguia multimídia, tecnologia disponibilizada também na versão infantil.

Do mesmo modo, foi a internet que possibilitou que o cidadão da Espanha conhecesse o Museu da Língua Portuguesa ${ }^{6}$ e se inteirasse de que, após um incêndio que ocorreu no ano de 2015, o Museu está fechado para reformas. Diante da impossibilidade de realizar uma visita in loco, o espanhol entra no site da instituição e percebe que no primeiro andar do edifício havia uma sala para realização de exposições temporárias; que o segundo piso abrigava uma grande tela de projeção de conteúdos imagéticos e sonoros para destacar o uso da língua portuguesa no cotidiano, além de outras instalações interativas, como o recurso que propiciava que os visitantes descobrissem a origem e significado de algumas palavras do idioma português; e de que havia no terceiro andar uma sala que evidenciava textos da literatura brasileira refletindo no teto e no chão obras de autores como Machado de Assis, Oswald de Andrade e Gonçalves Dias.

As situações que envolvem o visitante de nacionalidade espanhola podem ser fictícias, mas as possibilidades apresentadas sobre o uso da internet e dos sites dos museus são reais. $\bigcirc$ desenvolvimento tecnológico ampliou o acesso às informações ao contribuir para difusão dos bens culturais e trazer novas perspectivas para aproximação com o público. Contudo, apenas a disponibilização de conteúdos museológicos na rede é suficiente para garantir que a maioria das pessoas tenha acesso a eles? $\mathrm{Na}$ realidade, não. Para que isso seja possível é necessária a concepção de ambientes
5. O Museu Picasso está localizado em Barcelona, Espanha. Museu Picasso (2019).

6. O Museu da Língua Portuguesa está localizado em São Paulo, Brasil. Museu da Língua... (2020). 
7. Cf. Cambiaghi (2007).

8. Cf. Guimarães (2002).

9. Cf. Martins (2014).

10. Kastrup (2011, p. 89). que ofereçam recursos para atender a sociedade em sua diversidade linguística, cultural, visual, auditiva, cognitiva e motora. ${ }^{7}$ Um site que oferece informações apenas em português, por exemplo, será inacessível para pessoas que não compreendem o idioma. Do mesmo modo, uma página que disponibiliza imagens sem descrição compromete o acesso das pessoas com deficiência visual.

Em 2001, Rose Miranda já havia indicado em sua dissertação intitulada Informação e sites de museus de arte brasileiros: representação no ciberespaço que, nos países europeus, havia um número significativo de publicações a respeito do uso da internet pelas instituições museológicas, diferentemente do contexto brasileiro, que apresentava carência até mesmo de levantamentos sobre a quantidade de sites dos espaços museais. A representatividade dos estudos no campo cresceu no decorrer dos anos, contudo os projetos e pesquisas sobre acessibilidade nos sites dos museus ainda são prematuros. André Freire revelou, em 2008, em sua dissertação Acessibilidade no desenvolvimento de sistemas web: um estudo sobre o cenário brasileiro, que, mesmo diante da promulgação de leis, ainda são escassos os sites que podem ser considerados acessíveis e que esse fato se relaciona tanto à ausência da conscientização sobre a relevância da acessibilidade quanto à falta de conhecimento sobre a utilização de técnicas adequadas por aqueles que estão envolvidos nos projetos e desenvolvem as páginas da internet.

Sendo um dos objetivos do estudo incentivar a concepção de projetos acessíveis em museus, considerou-se o estudo de caso a metodologia mais adequada ao problema e às proposições que norteiam este trabalho. A pesquisa consiste em uma investigação baseada na análise da percepção dos participantes com deficiência visual em determinado ambiente e contexto, articulando-a à análise das informações geradas por uma ferramenta automática sobre esse contexto. Há a pretensão de que os dados empíricos, em diálogo com as reflexões teóricas, contribuam para verificar como a acessibilidade se configura nos sites dos museus. A inserção do público na pesquisa está relacionada às características do estudo de caso, as quais tendem a utilizar instrumentos como entrevistas e aplicação de questionários para investigação da realidade. Além disso, teóricos como Marcelo Guimarães ${ }^{8}$ e Patrícia Martins ${ }^{9}$ ressaltam a relevância da inserção dos sujeitos aos quais se destinam os projetos nas discussões de concepção e implementação de um estudo. A inserção dos sujeitos no desenvolvimento de estudos direcionados a eles diz respeito a uma metodologia inclusiva denominada "PesquisaCOM" e consiste em desenvolver a pesquisa "com os deficientes visuais e não sobre eles". ${ }^{10}$ 


\section{A CONDUÇÃO DO ESTUDO DE CASO: REVISÃO DE LITERATURA E REALIZAÇÃO DA INVESTIGAÇÃO EMPÍRICA}

A identificação prévia do público da pesquisa consiste em um importante elemento para a condução do estudo de caso, pois tem influência direta no planejamento da coleta de dados. Como destacado por Robert K. Yin, ${ }^{11}$ o investigador não controla o ambiente da coleta, portanto deve elaborar um plano flexível que preveja possíveis contratempos e possa se adequar à realidade investigada.

A seleção do público para a realização do estudo foi norteada pela revisão de literatura, mas, principalmente, motivada pelo desejo de dar continuidade ao caminho percorrido através do aprofundamento sobre conhecimentos adquiridos durante a graduação. $\bigcirc$ trajeto na graduação foi sendo delineado à medida que as atividades acadêmicas coincidiam com a prática profissional, em um período em que as experiências nos setores educativos e a participação em projetos relacionados à acessibilidade de instituições museológicas contribuíram para o desenvolvimento do trabalho de conclusão de curso. $\bigcirc$ processo de pesquisa na graduação - que teve como objetivo a investigação dos elementos necessários para promoção da acessibilidade em sites - apontou para a existência de estudos na área de acessibilidade na web, mas demonstrou a necessidade de pesquisas que servissem de subsídio e incentivo ao desenvolvimento de projetos e estudos relacionados ao campo museológico.

Para o estudo que resultou no presente artigo, optamos por trabalhar com pessoas com deficiência visual, haja vista os conhecimentos adquiridos em experiências anteriores nessa área somados à escassez de tempo para a produção da pesquisa. Como mencionado anteriormente, este texto é um desdobramento do estudo desenvolvido no mestrado. $\bigcirc$ curso, com duração de dois anos, direciona o primeiro ano para a realização de disciplinas e reelaboração do projeto de pesquisa, restando, portanto, um ano para o desenvolvimento do trabalho de campo ou ainda um período mais curto se consideramos o calendário escolar e a realidade a ser investigada.

Ainda que para este estudo se tivesse optado por trabalhar com pessoas com deficiência visual, seria preciso delimitar o público, considerando que dentro dessa categoria há outros grupos que, por possuírem características distintas, mudariam o curso da pesquisa. Nesse sentido, fez se a opção de realizar um estudo com a contribuição especificamente de pessoas que apresentassem ausência total da visão. $\bigcirc$ termo deficiência visual é utilizado para identificar pessoas que têm ausência total ou parcial da visão. Nesse segundo caso, utilizam-se também as terminologias baixa visão ou visão 
12. Amiralian (2004, p. 21).

13. No dicionário Aurélio (2002) cutâneo significa

"da pele ou a ela relativo; da cútis".

14. Ventorini (2007, p. 21).

15. Cf. Flor (2009). subnormal, sendo o primeiro termo mais comumente empregado: "A baixa visão é considerada uma dificuldade visual de graus variáveis, que causa incapacidade funcional e diminuição do desempenho visual." "12 Já a ausência total da visão, que pode ser conhecida também como cegueira, é a denominação utilizada para "aqueles que não conseguem ler o braile por meio da visão e para quem o tato, o olfato e a sensibilidade cutânea ${ }^{13}$ são os sentidos primordiais na apreensão do mundo externo". ${ }^{14}$

O diálogo com potenciais participantes da pesquisa foi iniciado por e-mail. Posteriormente, estendeu-se para ligações telefônicas e encontros presenciais à proporção que houve a percepção de que o contato direto com os sujeitos ampliava a possibilidade de maior compreensão do estudo e da colaboração dos participantes. Foram enviados treze e-mails sobre a pesquisa, sendo dois deles destinados a instituições de ensino que atendiam pessoas com deficiência e dez encaminhados a pessoas físicas. Duas das pessoas físicas encaminharam a pesquisa para os conhecidos, uma delas coordena o movimento que luta pelos direitos das pessoas com deficiência visual. As ligações telefônicas foram realizadas com cinco dos potenciais participantes e os encontros presenciais ocorreram com 11 deles, considerando que, em ambos os casos, dois correspondiam às instituições. No que tange às instituições, uma delas contribuiu na divulgação da pesquisa encaminhando um e-mail aos estudantes atendidos por ela, contudo, devido à políitica da instituição, o setor responsável pela divulgação não pôde disponibilizar os endereços eletrônicos dos estudantes e colocar o pesquisador em contato direto com eles. No último contato com a segunda universidade, fomos informados de que o processo que autoriza a realização da pesquisa e possibilita que esta encaminhe o e-mail a seus estudantes ainda estava em andamento. Em suma, recebemos retorno de uma das instituições e de seis dos contatos físicos, recebemos retorno de duas das três mensagens enviadas pelo Facebook, tendo em vista que, ao final, apenas uma pessoa respondeu ao questionário.

O número reduzido de participantes direcionou a pesquisa para uma análise qualitativa, e nesse sentido foram utilizados diversos instrumentos para explorar ao máximo a realidade investigada. $\bigcirc$ estudo está embasado por instrumentos técnicos - através de diretrizes que são referências mundiais e foram estabelecidas por especialista da área -, por um relevante arcabouço teórico como o estudo de Flor $^{15}$ que realizou um diagnóstico de acessibilidade dos museus virtuais considerados mais significativos pelo International Council of Museums/Conselho Internacional de Museus (ICOM) - e pela perspectiva de algumas pessoas com deficiência visual que, apesar de apresentarem características em comum, como o alto grau de escolaridade e no geral 
classificarem o conhecimento em informática como bom, vieram de contextos e realidades distintas no que tange a profissão e área de estudo. Uma das principais características do estudo de caso consiste na utilização de variadas fontes para exposição das evidências. ${ }^{16}$ É uma estratégia de pesquisa na qual o investigador se debruça sobre o objeto de estudo, buscando explicitá-lo plenamente e trazer à tona o maior número de informações. ${ }^{17}$ As evidências do presente estudo foram coletadas a partir de uma análise manual e automática da acessibilidade do site: questionário, ferramenta automática de avaliação de acessibilidade e revisão de literatura. Como resultado, este artigo apresenta uma abordagem metodológica para avaliação da acessibilidade voltada para pessoas com deficiência visual em sites, destaca instrumentos para levantamento de recursos necessário para promoção do acesso a esse público, traz exemplos de sites que têm ferramentas acessíveis e estabelece o diálogo com os potenciais usuários da página.

Para desenvolvimento e disponibilização do instrumento de investigação, foi necessário observar alguns fatores relacionados às concepções que orientaram o estudo e aos recursos que os respondentes utilizam para acessar a internet. No que diz respeito às concepções norteadoras, este estudo compreende que um espaço acessível é aquele em que é possível usufruir com conforto, autonomia e segurança, sem perda do conteúdo ou interferência na experiência. Nesse sentido, para que haja acessibilidade na internet é necessário que:

Todos os conteúdos/serviços estejam acessíveis, com acesso facilitado, da forma mais intuitiva, e com menor esforço, para o maior número possível de usuários, independente de suas culturas, experiências, deficiências, sistemas e dispositivos utilizados. ${ }^{18}$

A disponibilização de recursos de modo fácil, intuitivo e que exija menor esforço implica na configuração de ambientes de fácil interpretação, com linguagem clara, informações simples e objetivas, possibilitando o acesso à diversidade do público. É, portanto, equívoca a ideia de que a acessibilidade na internet diz respeito apenas às pessoas com deficiência. Na realidade, diz respeito a todos. Contudo, é importante considerar as características individuais para o oferecimento de mecanismos adequados à promoção de um "acesso universal". Essa é uma perspectiva que vai ao encontro de um conceito utilizado regularmente no que se refere à acessibilidade: o design universal (DU). Segundo Cambiaghi, ${ }^{19}$ o termo foi inicialmente utilizado pelo arquiteto Ronald Mace, tendo como objetivo o desenvolvimento de produtos, serviços e ambientes acessíveis ao maior número de pessoas possíveis, considerando as condições físicas, cognitivas, socioeconômicas e culturais. Posteriormente, a Universidade da Carolina do Norte, nos Estados
16. Cf. Yin (2001)

17. Cf. Alves (2007).

18. Soares (2013, p. 11).

19. Cf. Cambiaghi (2007). 
20. Para o texto sobre os sete princípios do Design Universal aplicado ao site dos museus, cf. Silva; Lopes (2016).

21. Teixeira; Okimoto; Heemann (2015, p. 136).

22. Cf. Flor (2009).

23. Ibid., p. 43.

24. Queiroz (2009, p. 45).

25. Informações baseadas na publicação do Departamento de Governo eletrônico, cf. EMAG (2014).
Unidos, publicou os Sete Princípios do Design Universal, ${ }^{20}$ a fim de orientar a criação de projetos baseados no DU. A perspectiva do DU enfatiza a relação do sujeito com o ambiente, produto e o serviço. "Esta linha de raciocínio dá enfoque à capacidade individual em vez da deficiência, utilizando como argumento que a não inclusão está na má concepção de ambientes e produtos". ${ }^{21}$

Sobre os recursos a serem observados na elaboração dos instrumentos de pesquisa, partimos do pressuposto de que o usuário com deficiência visual geralmente vai navegar pelas páginas da internet fazendo uso do leitor de tela, um software que, segundo Flor: 22

Interpreta o conteúdo de uma página e manda as informações para um sintetizador de voz (saída em áudio) ou monitor em braile (saída táctil). Nenhuma imagem que não possua equivalente textual é capaz de ser lida. $O$ software ainda pode ter problemas na leitura de colunas, tabelas e frames, já que ela é horizontal, o que pode ocasionar a mistura de textos, imagens e links. ${ }^{23}$

A navegação é feita a partir do uso do teclado e os comandos são realizados com combinações das teclas. Para compreensão da funcionalidade dos leitores de tela, é necessário esclarecer que esse programa não tem apenas a capacidade de leitura, mas também de descrição. "Dessa forma, quando ele passa por uma marcação de um link, ele sintetiza a palavra link para que o usuário possa saber da existência desse elemento naquele texto". ${ }^{24}$ Ao responder ao questionário, os participantes do estudo indicaram quais são os leitores de tela que geralmente utilizam para navegar na internet. Foram mencionados quatro softwares (quadro 1).

\section{Quadro 1 - Leitores de tela utilizados pelos participantes da pesquisa}

\begin{tabular}{|l|l|l|}
\hline Leitor de tela & \multicolumn{1}{|c|}{ Informações sobre o leitor ${ }^{25}$} & \multicolumn{1}{|c|}{$\begin{array}{c}\text { Número de } \\
\text { participantes que } \\
\text { utilizam o leitor }\end{array}$} \\
\hline NVDA & $\begin{array}{l}\text { Gratuito e de código aberto. } \\
\text { Teve início em } 2006 \text { na Austrália }\end{array}$ & 3 \\
\hline Virtual Vision & $\begin{array}{l}\text { Software comercializado. } \\
\text { Desenvolvido em 1997 no Brasil. }\end{array}$ & 2 \\
\hline Voice Over & Leitor de tela integrado aos aparelhos da empresa Apple. & 2 \\
\hline JAWS & $\begin{array}{l}\text { Software comercializado. } \\
\text { Lançado em } 1989 \text { na Flórida }\end{array}$ & 1 \\
\hline
\end{tabular}

Fonte: elaboração própria, com dados coletados através de aplicação do questionário e revisão de literatura 
Como sintetizado no quadro 2, o grupo que contribui para o estudo é composto por oito pessoas: duas mulheres e seis homens com idades entre 24 e 48 anos. Observa-se que os participantes têm alto grau de escolaridade, considerando que quatro possuem pós-graduação, dois são graduados e dois estão cursando o ensino superior. Dentre os participantes que concluíram a graduação, um deles fez mais de um curso, a saber: Direito, Filosofia e Teologia. No que diz respeito à informática, cinco dos respondentes classificaram seu conhecimento como bom, dois disseram que são regulares e um assinalou ser ótimo. Há um item no questionário que pergunta se os participantes desejam se identificar no estudo. Três deles optaram pelo direito de se manter no anonimato, portanto daremos nomes fictícios a todos, a fim de acompanhar o pensamento e as opiniões de cada um sem identificá-los.

\section{Quadro 2 - Perfil dos participantes do estudo}

\begin{tabular}{|l|l|l|l|l|}
\hline Nome fictício & \multicolumn{1}{|c|}{ Sexo } & Idade & \multicolumn{1}{|c|}{$\begin{array}{l}\text { Formação/Profissão ou área de } \\
\text { estudo }\end{array}$} & $\begin{array}{l}\text { Como classifica } \\
\text { seu conhecimen- } \\
\text { to em informática }\end{array}$ \\
\hline Ângela & Feminino & 39 & Pós-graduada em História & Regular \\
\hline Gabriela & Feminino & 25 & $\begin{array}{l}\text { Graduanda em Ciências Sociais (8º } \\
\text { período) }\end{array}$ & Bom \\
\hline Alexandre & Masculino & 48 & $\begin{array}{l}\text { Pós-graduado em Gestão Pública. } \\
\text { Funcionário público }\end{array}$ & Bom \\
\hline Francisco & Masculino & & Mestre em Física & Regular \\
\hline Inácio & Masculino & 40 & $\begin{array}{l}\text { Graduado em Direito, Filosofia e Teo- } \\
\text { logia. Funcionário público }\end{array}$ & Bom \\
\hline Ítalo & Masculino & 24 & $\begin{array}{l}\text { Especialista em Gestão de Negócios. } \\
\text { Palestrante e consultor }\end{array}$ & Ótimo \\
\hline Rômulo & Masculino & 32 & Graduando em Direito (3 período) & Bom \\
\hline Washington & Masculino & & Pedagogo & Bom \\
\hline
\end{tabular}

Fonte: elaboração própria, com dados coletados através de aplicação do questionário

No que tange à eleição do site para realização da pesquisa, a opção pelo MAO é justificada por ser um espaço frequentemente abordado em trabalhos acadêmicos, mas, sobretudo, porque, ainda no período exploratório do estudo, alguns participantes sugeriram o site do museu para investigação, devido aos convites realizados para visitar a exposição durante a implementação de projetos de acessibilidade infraestrutural e por considerarem a relevância do acervo do museu na representatividade da história social. Se mesmo diante das justificativas 
26. Catel (2005, p. 526), grifo nosso.

27. Cf. Braga (2014). que se apresentaram durante o período exploratório do estudo houvesse alguma hesitação para determinação da realidade a ser investigada, esta foi eliminada com a revisão de literatura em que alguns elementos reafirmaram a escolha. $\bigcirc$ site do MAO se mostrou adequado, principalmente, em razão do histórico da instituição. Na tentativa de refazer o caminho de constituição do museu, percebemos que suas propostas iam ao encontro das proposições deste estudo, na medida em que as dimensões social e educativa eram evidenciadas nas ações empreendidas pela instituição. A pesquisadora Luciana Sepúlveda realizou uma entrevista com Pierre Catel no ano de inauguração do Museu de Artes e Ofícios. $\bigcirc$ museólogo responsável pelo projeto do MAO revelou em seu discurso a pretensão de construção de um espaço de democratização do conhecimento, que abarcasse justamente aqueles que menos tinham acesso aos bens culturais:

O elemento indispensável, em seguida, foi a reflexão sobre a finalidade com a qual se fazia esse museu. Não era com a finalidade de conservação das coleções, uma vez que elas já estavam protegidas, mas com a finalidade, justamente, de difusão, de vulgarização de um conhecimento [...] nosso objetivo era ter um público bem popular, uma vez que íamos trabalhar num terreno para difundir um conhecimento popular, e era preciso restituir uma identidade, um interesse ao trabalho manual e ao trabalho técnico. Aliás, era preciso se situar num lugar onde o público já estivesse antes. Foi por isso que pensamos na possibilidade de fazer esse museu numa estação de metrô [...] é evidente que aqueles que queremos atingir é o público da periferia urbana, que não tem, forçosamente, muitos espaços culturais à disposição. São pessoas que, nós sabemos, estão cansadas à noite, quando voltam do trabalho. Se queremos que eles venham ao museu por um tempo, é preciso atraílos, mas não com grandes teorias. Em compensação, sabemos que é um espaço facilmente acessível para eles, porque há o metrô. ${ }^{26}$

Localizado na Praça Rui Barbosa, mais conhecida como Praça da Estação, MAO foi inaugurado no final de 2005, abrindo as portas ao público em 2006. O museu abriga a coleção que, a princípio, foi constituída por Flávio Gutierrez, deixada para sua filha Ângela Gutierrez e doada ao patrimônio público no ano de inauguração da instituição. $\bigcirc$ acervo, que atualmente aceita doações, é constituído por artefatos que remetem ao período pré-industrial, com objetos que representam a fase da indústria manufatureira, como mobiliários, utensílios, máquinas e equipamentos domésticos e industriais. ${ }^{27} \mathrm{Na}$ área de acessibilidade, tendo em vista a infraestrutura adequada para receber visitantes idosos e com dificuldade de locomoção, o Museu de Artes e Ofícios dispõe de uma infraestrutura com rampas, elevadores, plataformas elevatórias, sanitários e bebedouros adaptados. No que se refere aos visitantes com deficiência visual e auditiva, o Museu diz oferecer objetos do acervo e maquetes táteis, assim como 
mediação especializada. ${ }^{28}$ Vale a pena ressaltar que o site do MAO disponibiliza fotos sobre os serviços de acessibilidade ofertados em sua infraestrutura.

\section{A REDE MUNDIAL DE COMPUTADORES EM FOCO: PADRÕES DE ACESSIBILIDADE NO MUNDO E NO BRASIL}

Ainda que na contemporaneidade exista um significativo arcabouço legislativo e teórico com o objetivo de promover a acessibilidade - seja infra estrutural, seja tecnologicamente -, na prática as ações voltadas para este campo ainda caminham a passos lentos. Com base na afirmação de Freire ${ }^{29}$ - de que este fator se relaciona tanto com a ausência da conscientização sobre a relevância da acessibilidade quanto com a falta de conhecimento sobre a utilização de técnicas adequadas por aqueles que estão envolvidos nos projetos e desenvolvem as páginas da internet -, a presente pesquisa visa evidenciar, através de um estudo de caso, os recursos existentes para investigação e promoção da acessibilidade nos sites, especialmente em relação aos museus que, gradativamente, ampliaram sua função social e educativa, com iniciativas que visavam à aproximação de um público com perfil cada vez mais diversificado. No entanto, ainda apresentam escassez de estudos e projetos nesse campo.

Como descrito anteriormente na abordagem da metodologia, a investigação sobre a acessibilidade dos sites de instituições museológicas, embasada na página do Museu de Artes e Ofícios, foi realizada através de uma análise automática com a utilização da ferramenta HERA, que realiza uma análise prévia dos recursos de acessibilidade de páginas na internet e uma análise manual correspondente à avaliação humana, que conta com a perspectiva dos potenciais usuários e observações da pesquisadora baseadas na revisão de literatura e estudos relacionados ao tema. As principais referências para análise automática e manual são as diretrizes de acessibilidade desenvolvidas pelo grupo W3C. Desde sua concepção, essas diretrizes se tornaram referência mundial para elaboração de documentos que visam orientar a acessibilidade nas páginas ou implementar o projeto na rede mundial de computadores. Apesar de sua relevância, esse documento não foi o primeiro a ser elaborado no âmbito informacional.

Datam de 1997 as primeiras iniciativas que visavam estabelecer parâmetros de acessibilidade na internet. Países como Canadá, Estados Unidos e Austrália teriam sido os pioneiros nessas ações. Com o objetivo de reduzir as barreiras nos sistemas e tecnologias de comunicação e informação, o governo dos EUA instituiv em 1998 a Section 508, lei que estabelece que as tecnologias eletrônicas e de comunicação e informação dos órgãos federais deveriam ser acessíveis às pessoas com deficiência.
28. Cf. Silva; Oliveira; Mourthé (2012).

29. Cf. Freire (2008). 
30. Ibid.

31. Em francês é denominada Normalisation des sites Internet-NSI 1.0. Em inglês Common Look and Feel-CLF 1.0.

32. Cf. Gouvernement du Canada (2013).

33. Cf. Rocha; Duarte (2012).

34. Entre outras determinações a Lei 10.048/2000 estabelece o atendimento preferencial a idosos, pessoas com deficiência, com crianças de colo, com obesidade, gestantes e lactantes. Cf. Brasil (2000a).

35. Entre outras determinações a Lei 10.098/2000 dispõe de forma geral sobre a regras e os critérios para promoção de acessibilidade em transportes coletivos, espaços públicos e sistemas de comunicação. Cf. Brasil (2000b).

36. Cf. Brasil (2004).
De acordo com o texto da Section 508, a inacessibilidade das tecnologias influencia a capacidade dos indivíduos em obter informações com facilidade e rapidez. ${ }^{30} \bigcirc$ governo canadense também começou a tomar medidas para promoção da acessibilidade nos sites a partir de 1988, quando publicou um guia reunindo orientações e ferramentas comuns para acessibilidade na internet. Mais tarde, em maio de 2000, o Canadá aprovou a versão 1.0 da Normalisation des Sites Internet $(N S I),{ }^{31}$ seu primeiro conjunto de padrões de acessibilidade para conteúdo da web. A NSI tornava obrigatória a acessibilidade nos sites e aplicativos governamentais, exigindo que, no prazo de dois anos, as páginas da internet relacionadas ao governo atendessem às Diretrizes de Acessibilidade para o Conteúdo da Web - WCAG 1.0. ${ }^{32}$ A primeira versão do documento que continha as diretrizes, o Web Content Accessibility Guidelines, foi publicada pelo W3C em maio de 1999.

O consórcio, constituído por empresas e estudiosos advindos de diversas localidades do mundo, foi fundado em 1994 pelo britânico Berners Lee. Não foi a primeira vez que o cientista da computação teria trazido contribuições para o âmbito da rede mundial de computadores. Tim Bernes Lee, juntamente com Robert Cailliau, foi responsável por coordenar o grupo que, no início da década de 1990, inventou a grande teia mundial de computadores. Mais conhecido como WWW - World Wide Web, esse novo recurso tecnológico possibilitou a difusão da internet na sociedade e a criação dos sites. A fundação do W3C em 1994 evidenciou o objetivo de explorar ao máximo o potencial da internet por meio da elaboração de padrões que visavam tornar os conteúdos universalmente acessíveis. Esse objetivo se tornou real e tangível no ano de 1999, quando foi criado, dentro do W3C, o Web Accessibility Initiative (WAl), grupo de trabalho responsável por desenvolver as diretrizes que logo se tornariam referência mundial na promoção da acessibilidade na internet ${ }^{33}$ e que ganharia a versão 2.0 em dezembro de 2008.

No Brasil, o direito do acesso às informações vinculadas aos órgãos públicos foi ratificado no dia 2 de dezembro de 2004 pelo decreto n 5.296, através do Art. 47, que determina a obrigatoriedade da acessibilidade nas páginas da internet pertencentes ou gerenciadas por organizações governamentais. $O$ documento, que regulamenta as leis $10.048 / 2000^{34} \mathrm{e}$ $10.098 / 2000,35$ dispõe, de forma geral, sobre a regras e os critérios para promoção de acessibilidade em transportes coletivos, espaços públicos, edificações de uso coletivo e sistemas de comunicação e informação. ${ }^{36}$

Com o objetivo de estimular a implementação do decreto que torna obrigatória a acessibilidade nos portais dos órgãos governamentais brasileiros, foi disponibilizado em 2004 o Modelo de Acessibilidade em Governo Eletrônico eMAG (figura 1). O modelo, que foi criado pelo Departamento de Governo 
Eletrônico em parceria com a ONG Acessibilidade Brasil, traz recomendações que visam tornar os sites mais acessíveis. A ferramenta - que após algumas revisões ganhou em 2008 a versão 3.0 e, atualmente, está na versão 3.1 - foi elaborada a partir do estudo de 14 normas internacionais sobre acessibilidade digital, entre elas a Section 508, a Normalisation des Sites Internet (NSI), as diretrizes irlandesas de acessibilidade e outros documentos de países como Espanha e Portugal. ${ }^{37}$ Tendo em vista as demandas locais e as orientações internacionais, a página do eMAG reúne conceitos e informações dos elementos de acessibilidade que por lei devem estar presentes em todos os portais governamentais (figura 1).

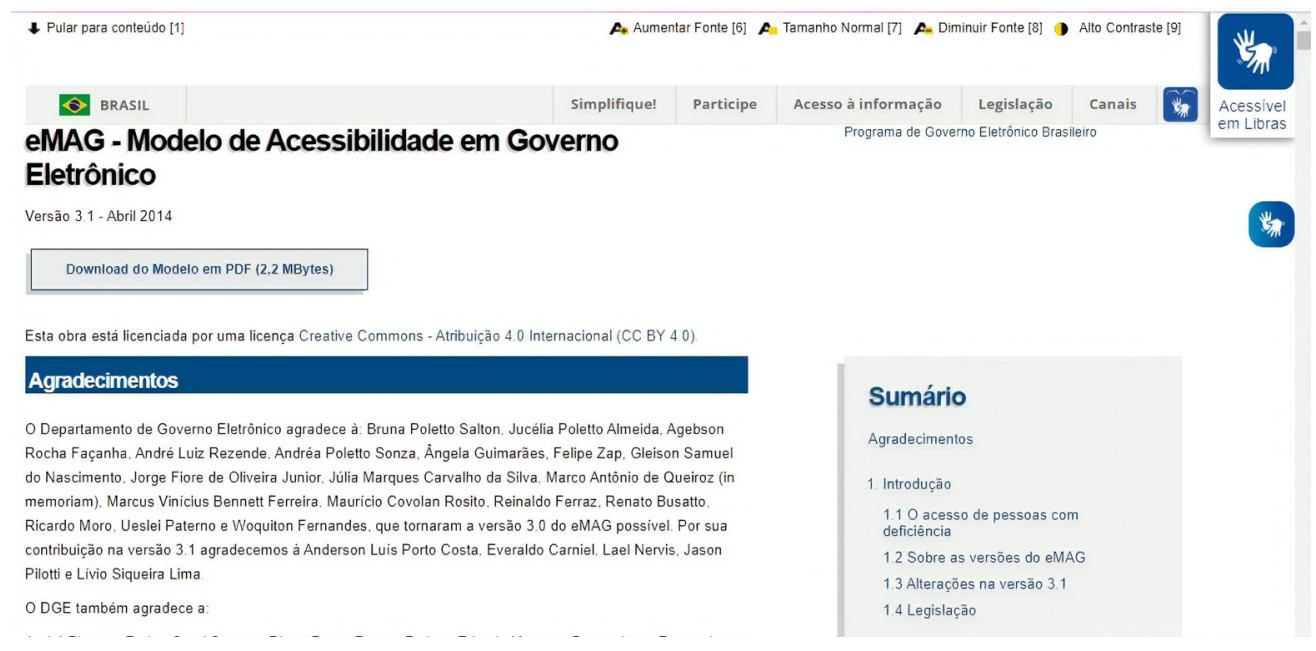

Figura 1 - Modelo de Acessibilidade em Governo Eletrônico e-MAG, 2017

Ainda que não sejam encontradas iniciativas legais que visem garantir especificamente o direito de acessibilidade das páginas na internet nos âmbitos cultural e educacional, que são as áreas estudadas no presente estudo, existem arcabouços teóricos e legislativos que corroboram para que essas ações se estendam a outros campos. Na medida em que há um reconhecimento da internet como veículo de comunicação e informação, sendo um novo recurso inserido na dinâmica social, cultural e muitas vezes educacional, conclui-se que, mesmo implicitamente, o direito de acessibilidade na rede mundial de computadores está contemplado desde os princípios legais que regularizaram o acesso universal à informação, como aqueles que abordam a cultura e a educação.

$\bigcirc$ direito informacional é estabelecido desde a publicação da Declaração Universal dos Direitos Humanos, ${ }^{38}$ tendo em vista que esse documento faz referência, em seu Art. 19, à liberdade de expressão e opinião, o direito de todo ser humano pela busca, obtenção e transmissão de informações independentemente das fronteiras. $\bigcirc$ 
39. Cf. Brasil (1988).

40. Cf. Brasil (2009), grifo nosso.

41. Ibid. acesso aos bens culturais também é contemplado como direito fundamental do ser humano, na medida em que o Art. 27 assegura a todos a participação livre na vida cultural da comunidade. Mais tarde, esses direitos serão ratificados em território nacional na Constituição de 1988, que dedica o capítulo III a educação, desporto e cultura; o capítulo IV, a ciência e tecnologia, e o capítulo IV, à comunicação social. ${ }^{39}$

No âmbito das instituições museológicas, a Lei № 11.904/2009 que, entre outros aspectos, estabelece o estatuto dos museus, traz diversas considerações que legitimam os processos de acessibilidade, na medida em que há a reafirmação do papel dos museus enquanto espaços que resguardam e preservam os bens da sociedade e que, portanto, devem garantir o acesso de todos. $\bigcirc$ art. $2^{\circ}$ do capítulo I estabelece como princípios fundamentais dos museus:

I - A valorização da dignidade humana?

II - A promoção da cidadania?

III - o cumprimento da função social?

IV - A valorização e preservação do patrimônio cultural e ambiental?

V - A universalidade do acesso, o respeito e a valorização à diversidade cultural?

$\mathrm{VI}-\mathrm{O}$ intercâmbio institucional. ${ }^{40}$

A lei, promulgada em 2009, também evidencia as ações educativas e comunicativas como recursos que potencializam e podem ampliar o acesso da sociedade aos bens culturais. Os artigos 29 e 31 destacam que:

Art. 29. Os museus deverão promover ações educativas, fundamentadas no respeito à diversidade cultural e na participação comunitária, contribuindo para ampliar o acesso da sociedade às manifestações culturais e ao patrimônio material e imaterial da Nação.

$[\ldots]$

Art. 31. As ações de comunicação constituem formas de se fazer conhecer os bens culturais incorporados ou depositados no museu, de forma a propiciar o acesso público. ${ }^{41}$

Nessa perspectiva, os museus estariam contribuindo para o desenvolvimento social e cumprindo com pressupostos legais ao implementarem ações de acessibilidade e promoverem o contato das pessoas com um patrimônio que por direito todos deveriam 
ter acesso - seja presencial, seja virtualmente -, tendo em vista que os monumentos considerados patrimônio da humanidade, por exemplo, podem não estar acessíveis a todos, em termos econômicos e geográficos. Contudo, a representação e as informações sobre eles podem estar ao alcance de muitas pessoas por meio da internet.

Para Castells, ${ }^{42}$ a internet não é apenas um dos principais meios de comunicação da sociedade, mas é também um sistema de expressão cultural que permite a realização de conexões de acordo com nossos interesses e sentimentos. Nesse sentido, afirma o teórico:

A Internet tem o efeito de permitir que nos liguemos seletivamente a diferentes formas de expressão cultural e a diferentes sistemas eletrônicos de comunicação e reunir - de acordo com o que cada um de nós deseja, pensa ou sente - distintos elementos desse sistema de comunicação, de modo que o hipertexto vive em cada um de nós. ${ }^{43}$

Os próximos subtítulos têm como objetivo um aprofundamento das Diretrizes de Acessibilidade para os conteúdos da internet, apresentando melhor o documento desenvolvido pelo W3C, o Web Content Accessibility Guidelines - WCAG 2.0.

\section{A COMPOSIÇÃO DO RELATÓRIO DO ESTUDO DE CASO A PARTIR DO GUIA DE ACESSIBILIDADE E DE SUAS DIRETRIZES}

Como observado anteriormente, os instrumentos de pesquisa utilizados para coleta de dados do presente estudo foram inspirados nas diretrizes do WCAG 2.0. Nesse sentido, a exposição dos resultados seguirá a estrutura do guia, o que implica o conhecimento mais amplo do documento.

Web Content Accessibility Guidelines, elaborado pelo Consórcio W3C, é composto por 12 diretrizes. Tidas como orientações que visam tornar os conteúdos das páginas na internet mais acessíveis, as diretrizes são organizadas em torno de quatro princípios que sustentam a acessibilidade de um site. Afirma-se, portanto, que uma página acessível aos diversos usuários é aquela que possui conteúdo perceptível, operável, compreensível e robusto. ${ }^{44}$ Para cada diretriz são atribuídos critérios de sucesso, ou seja, afirmações testáveis que podem ser utilizadas para verificar se há acessibilidade no site. São, portanto, requisitos a serem cumpridos. Esses critérios são classificados em níveis e, quanto maior o nível, mais acessível o site tende a ser. As páginas na internet podem ser classificadas no nível A, quando atendem a todos os 
critérios de prioridade 1; nível AA, estando de acordo com todas as recomendações de prioridade 1 e 2, e nível AAA, na medida em que contemplam as orientações de prioridade 1, 2 e 3 (figura 2). $\bigcirc$ guia de acessibilidade ainda apresenta técnicas para o atendimento das diretrizes e dos critérios de sucesso.

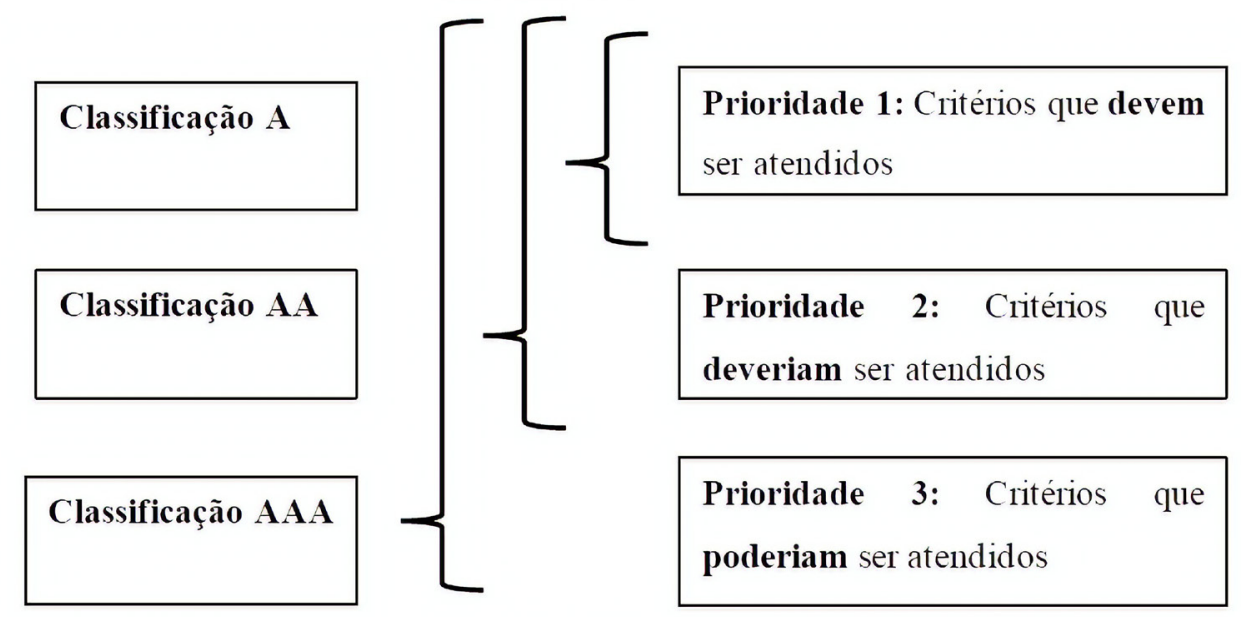

Figura 2 - Níveis de conformidade da acessibilidade nos sites, 2017. Elaboração própria, a partir da dissertação de Freire (2009, p. 15).

Resumindo, as diretrizes são recomendações de acessibilidade que foram inspiradas em quatro princípios. Para verificar como se configura a acessibilidade no site do Museu de Artes e Ofícios, objeto do presente estudo, é necessário averiguar se a forma de disponibilização dos conteúdos da página segue alguma orientação de acessibilidade, alguma diretriz. Para que o conteúdo esteja de acordo com a diretriz, ele deve seguir alguns critérios de sucesso, ou seja, alguns requisitos devem ser considerados para verificar se o site atende às diretrizes. As técnicas são as alternativas para cumprimento do requisito. Abaixo, a ilustração da estruturação desses elementos no guia de acessibilidade (figura 3).

Compreende-se que a acessibilidade não diz respeito apenas às pessoas com deficiência, sendo um ambiente acessível aquele capaz de atender a população de forma igualitária ou equivalente, em sua diversidade linguística, cultural, visual, auditiva, cognitiva e motora. Contudo, está claro também que, para promoção de um "acesso universal", é necessário considerar as características individuais para o oferecimento de recursos e espaços adequados às habilidades de cada um. Tendo isso em vista, concentraremos a atenção apenas nas diretrizes, critérios e técnicas que contemplam o público deste trabalho, verificando, através da análise humana e automática, se o Museu de Artes e Ofícios disponibiliza em 
seu site conteúdos que seguem alguma das recomendações selecionadas. As diretrizes e os critérios foram agrupados em três grupos de acordo com os princípios que inspiraram a criação de cada um e serão apresentados no próximo subtítulo.

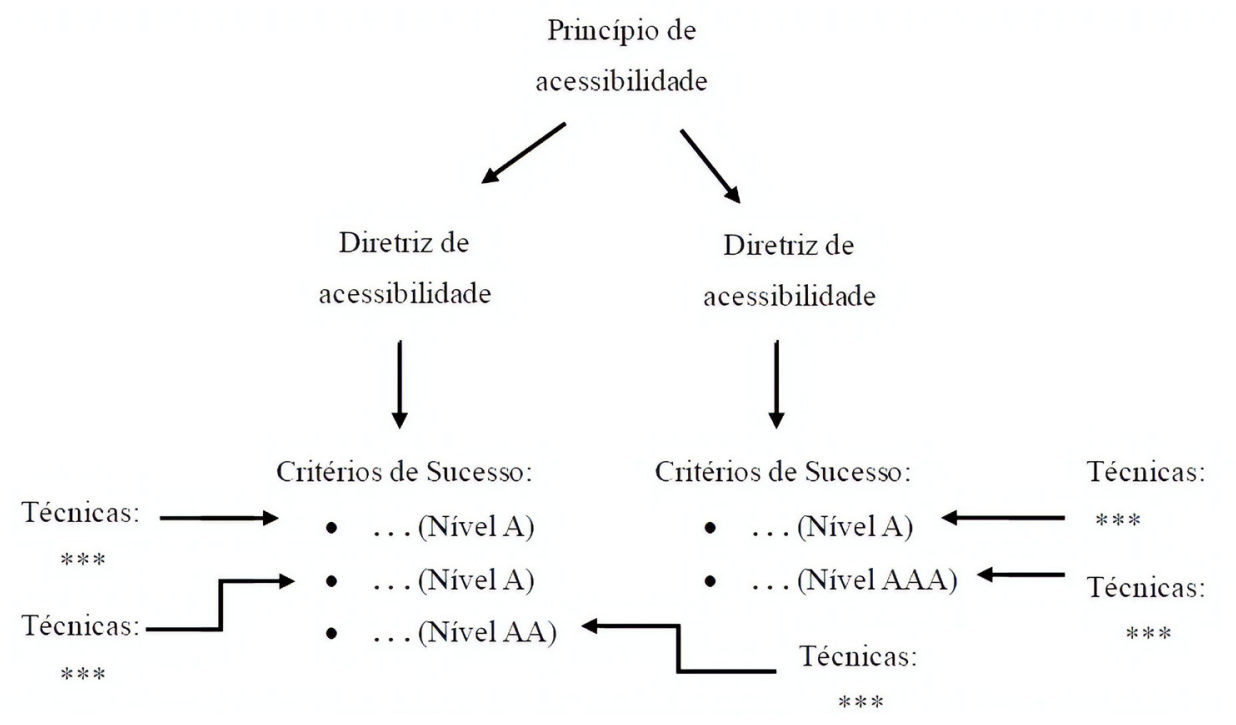

Figura 3 - llustração da estrutura do Guia de Acessibilidade para os conteúdos da Internet, 2017. Elaboração própria, a partir do WCAG 2.0 (W3C, 2008).

\section{ESTUDO DE CASO: ANÁLISE DAS DIRETRIZES DE ACESSIBILIDADE INSPIRADAS NO PRINCÍPIO PERCEPTÍVEL}

Alternativa para conteúdo não textual: essa, normalmente, é a diretriz em que os sites apresentam maior défice. Como mencionado, os leitores de tela geralmente não leem conteúdos imagéticos nem mídias, o que impossibilita a percepção desses conteúdos pelos usuários que fazem uso desse recurso. Nesse sentido, é recomendado que os sites apresentem alternativa textual com o propósito e informações equivalentes ao conteúdo não textual. Algumas alternativas dizem respeito a imagens acompanhadas de legendas ou textos descritivos. Há distintas técnicas para incorporação de textos em imagens. A mais comum é a incorporação por um código, através do atributo alt. Segundo Nielsen, ${ }^{45}$ esse código permite que um texto alternativo seja apresentado ao usuário que não tem acesso à imagem, ou por ter deficiência visual ou porque 
optou por desabilitar a exibição de imagens devido à velocidade de sua internet. $\bigcirc$ atributo alt (= alternativo) é recomendado para apresentação de informações sintéticas, textos curtos ou títulos para o conteúdo imagético. Para descrições mais detalhadas orienta-se o uso do atributo "LONGDESC" I= longa descrição) ou "D" link. Este último consiste em um link que redireciona o usuário para a página que contém o texto que traz detalhes sobre a imagem. ${ }^{46} \mathrm{Em}$ seguida, um exemplo encontrado na página do The British Museum, que faz uso do atributo alt para curta descrição de um conteúdo não textual (figura 5), - leitor de tela fará a leitura a partir do texto disponibilizado, identificando a imagem como: Edo bronze tusk-stand in the from of a human head. Nigeria, Benin. Para que o código ficasse visível foi utilizada a ferramenta HERA.

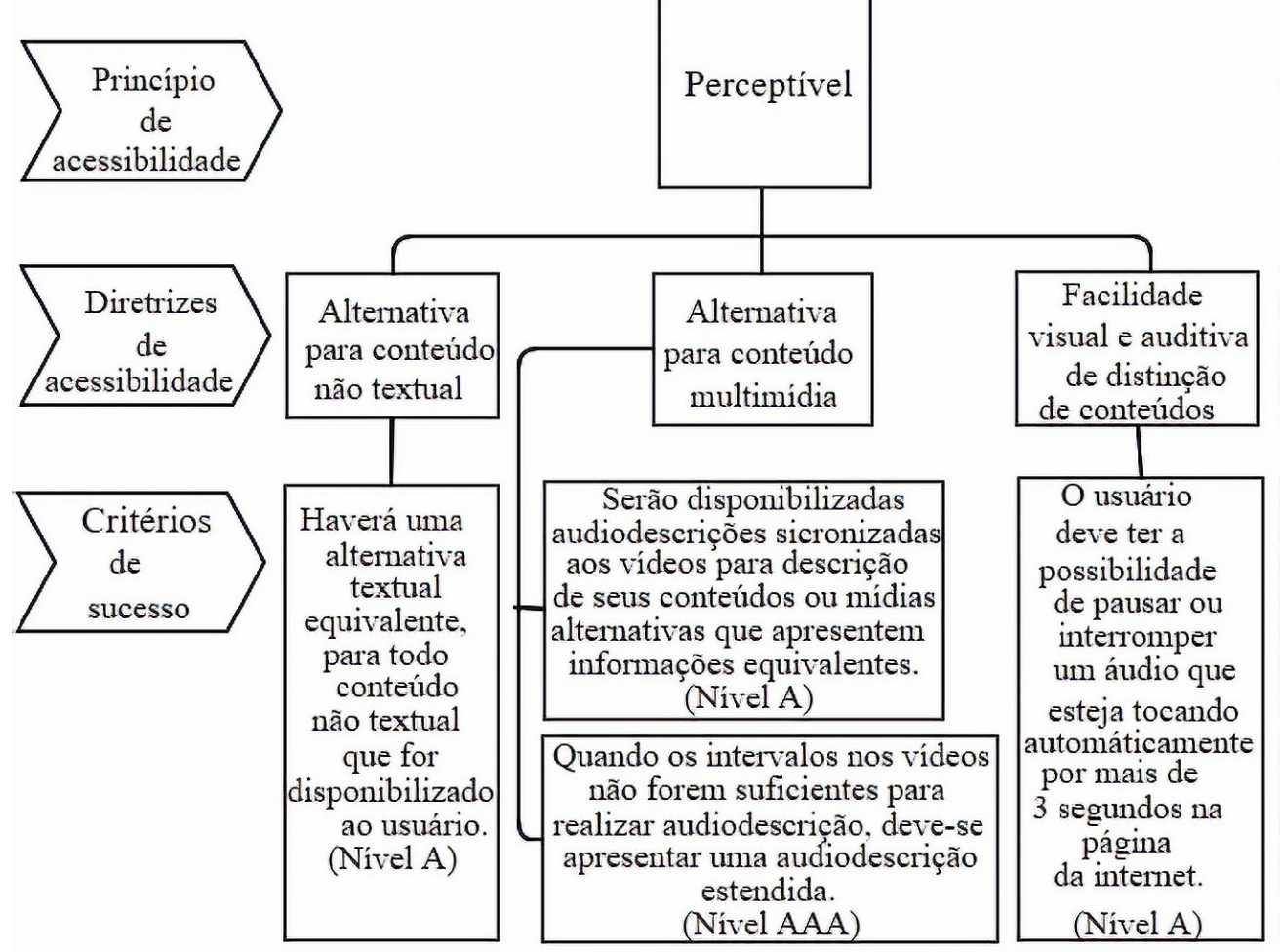

Figura 4 - Diretrizes de Acessibilidade baseadas no Princípio Perceptível, 2017. Elaboração própria, a partir do WCAG 2.0 (W3C, 2008). 


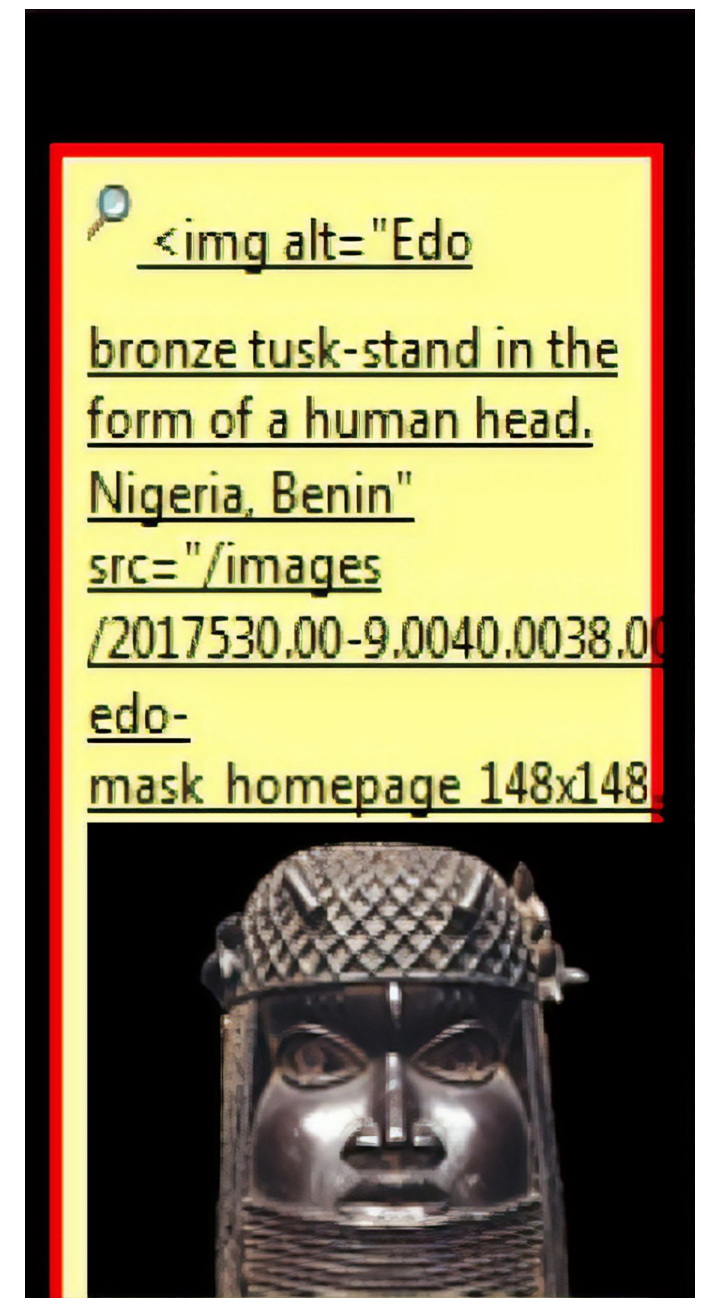

Figura 5 - Utilização do atributo alt para descrição do conteúdo imagético disponibilizado em uma página na Internet, 2018. Site do British Museum.

Ao serem questionados se tiveram dificuldades em compreender alguma informação com os recursos utilizados no site do Museu de Artes e Ofícios, sete dos cinco participantes da pesquisa assinalaram mais de uma das opções, afirmando que a ausência de textos que descrevessem imagens dificultou a compreensão de algumas informações. Dentre esses participantes, quatro ainda indicaram ter a compreensão dificultada pela ausência de descrição de vídeos e três assinalaram que os recursos presentes nos sites são insuficientes para compreensão do conteúdo. Apenas uma pessoa indicou que os recursos utilizados na página do MAO foram suficientes para compreensão das informações. Abaixo, o gráfico 1 sintetiza as opções selecionadas pelos participantes com base na visita ao site do museu. 


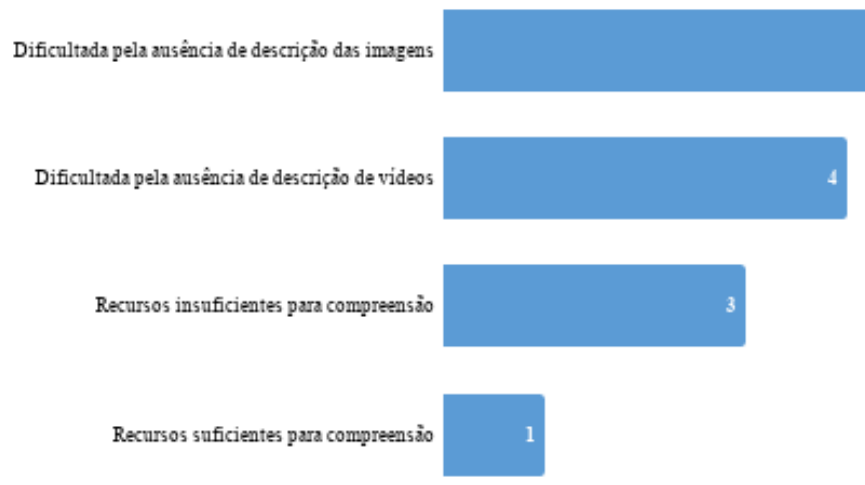

Número de participantes que asssinalaram a opçào. O grupo é constituído por 8 pessoas, que poderiam assinalar mais de uma opçào.

Gráfico 1 - Compreensão das informações disponibilizadas no site. Elaboração própria, com dados coletados através de aplicação do questionário.

Observa-se que a maioria dos participantes do estudo apontaram dificuldades de compreensão das informações do site do Museu de Artes e Ofícios. Uma das razões assinaladas foi a ausência de textos alternativos para conteúdos imagéticos. A página do MAO apresenta imagens que correspondem a fotografias de objetos do acervo, salas e espaços externos. Também há fotos sobre as atividades realizadas e sobre os serviços disponíveis, como visita de escolas e acessibilidade infraestrutural, além dos símbolos dos patrocinadores. A análise automática, realizada pela ferramenta HERA, indica que o site do museu faz uso do atributo alt, disponibilizando uma alternativa textual para as imagens, contudo alguns textos alternativos não são claros, dificultando a identificação do conteúdo imagético. Essa característica foi sinalizada, principalmente, em conteúdos imagéticos da página inicial: enquanto uma das imagens (figura 6) é identificada pelo leitor de tela como IMG_20170831_145942567, texto que corresponde ao atributo alt; a outra (figura 7) é identificada como Um atrapalho no trabalho.

Aprofundando ainda mais na visita ao site do MAO e acessando outras páginas arravés dos menus disponíveis na seção inicial, verifica-se que as demais imagens possuem textos alternativos mais claros. A página que traz informações sobre o acervo apresenta fotografias para ilustrar as coleções existentes. Em seguida, uma das fotografiias ilustra a coleção Ofícios de transporte (figura 8). A imagem é identificada pelo atributo alt como Ofícios do Transporte - Galeria A - Foto Daniel Mansur. 


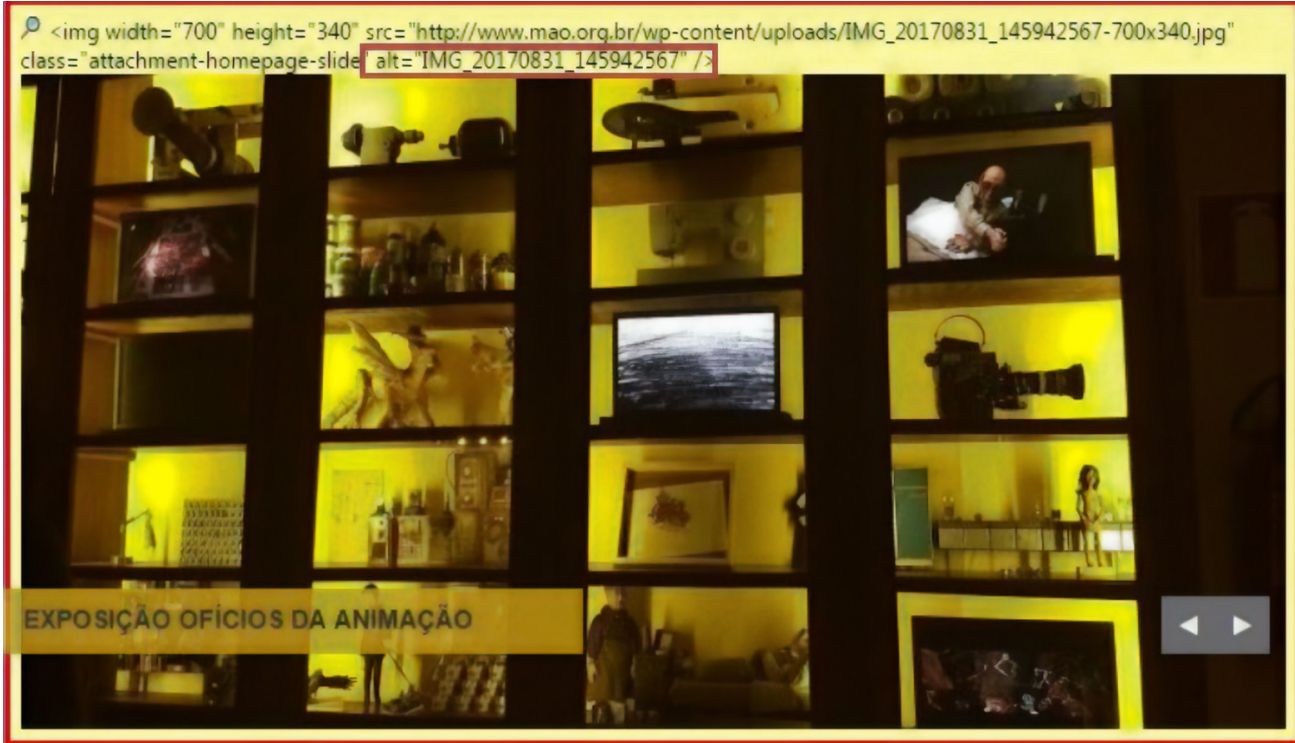

Figura 6 - Exibição de código de imagem pertencente à página inicial do site do MAO, com destaque para atributo alt, que corresponde ao equivalente textual do conteúdo imagético, 2018. Revisão do site com a utilização da ferramenta HERA.

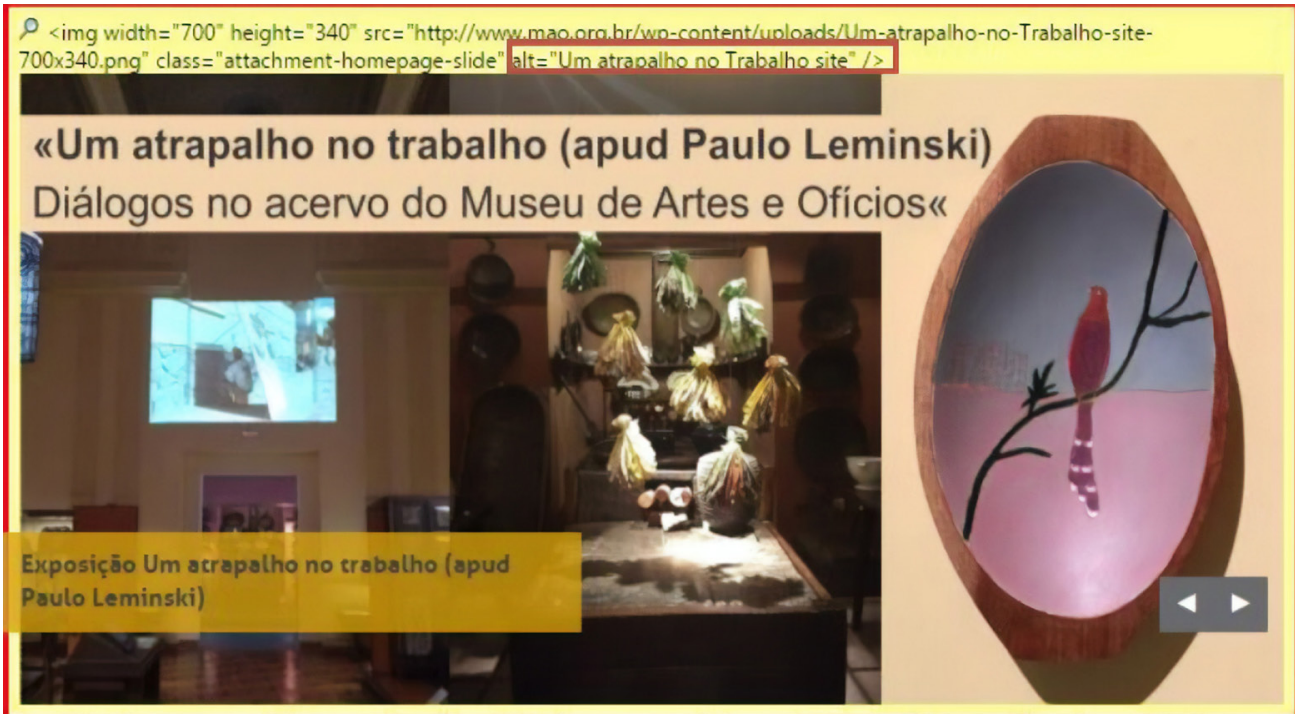

Figura 7 - Exibição de código de imagem pertencente à página inicial do site do MAO, com destaque para atributo alt, que corresponde ao equivalente textual do conteúdo imagético, 2018. Revisão do site com utilização da ferramenta HERA. 


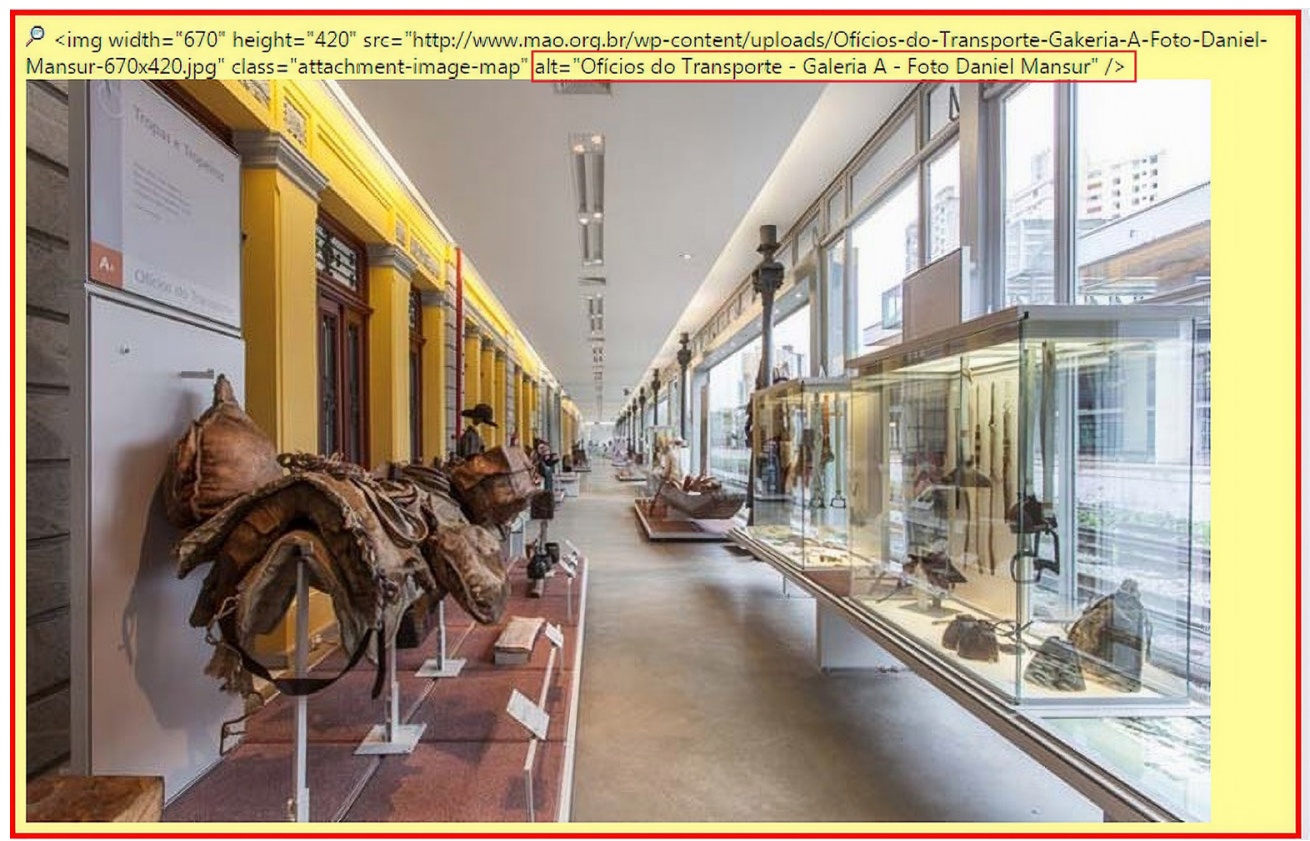

Figura 8 - Exibição de código de imagem pertencente à página sobre o acervo do $M A O$, com destaque para atributo alt, que corresponde ao equivalente textual do conteúdo imagético, 2018. Revisão do site com utilização da ferramenta HERA.

Como mencionado anteriormente, há outras técnicas que podem ser utilizadas com o objetivo de disponibilizar alternativas textuais para conteúdos imagéticos. $\bigcirc$ atributo alt é recomendado para descrições sintéticas, portanto, textos curtos como os apresentados no site do MAO. Contudo, se os desenvolvedores do site têm a pretensão de possibilitar que o usuário, além de perceber a imagem, saiba como ela é, tornam-se necessárias descrições mais detalhadas. Dessa forma, destacaremos algumas iniciativas promovidas por instituições museológicas com esse objetivo. $\bigcirc$ site do MoMA, por exemplo, faz uso de audiodescrições para apresentação de algumas obras presentes em seu acervo (figura 9). A ferramenta- que está disponível em português, francês, alemão, italiano, coreano, japonês, mandarim, espanhol e inglês - traz descrições de esculturas, painéis e pinturas do Museu de Arte Moderna, localizado em Nova York. São 29 obras audiodescritas. Com a utilização dessa ferramenta, os desenvolvedores do site demonstram estar atentos não apenas às pessoas com deficiência visual, mas ao visitante de outras nacionalidades, disponibilizando áudios em diferentes idiomas. Além disso, a possibilidade de ter acesso a algumas informações e ser apresentado a algumas das obras do acervo do museu pode instigar o visitante do site a realizar uma visita presencial. 


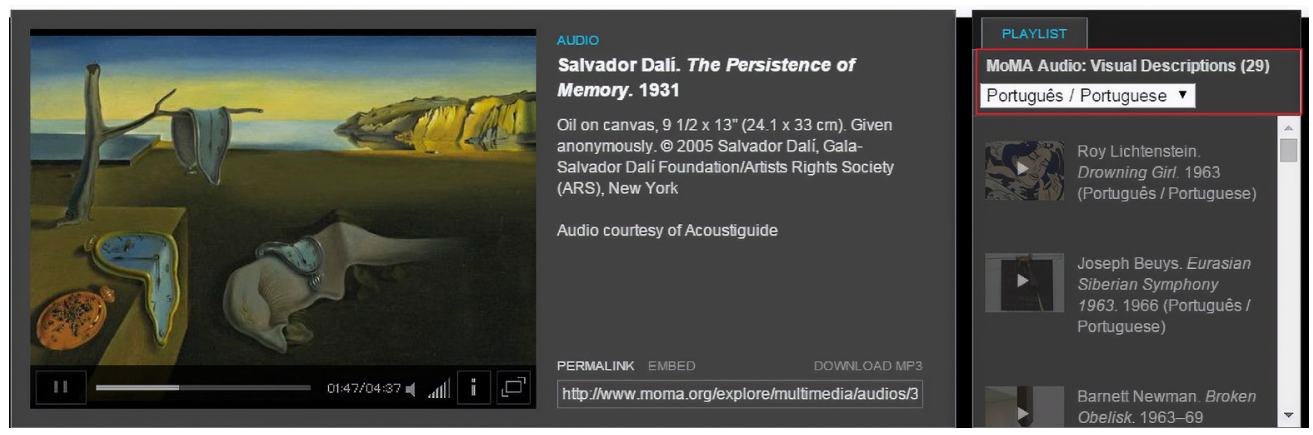

Figura 9 - Audiodescrição em português de obras do MoMA. A persistência da Memória - Salvador Dali, 1931, 2017. Site do MoMA.

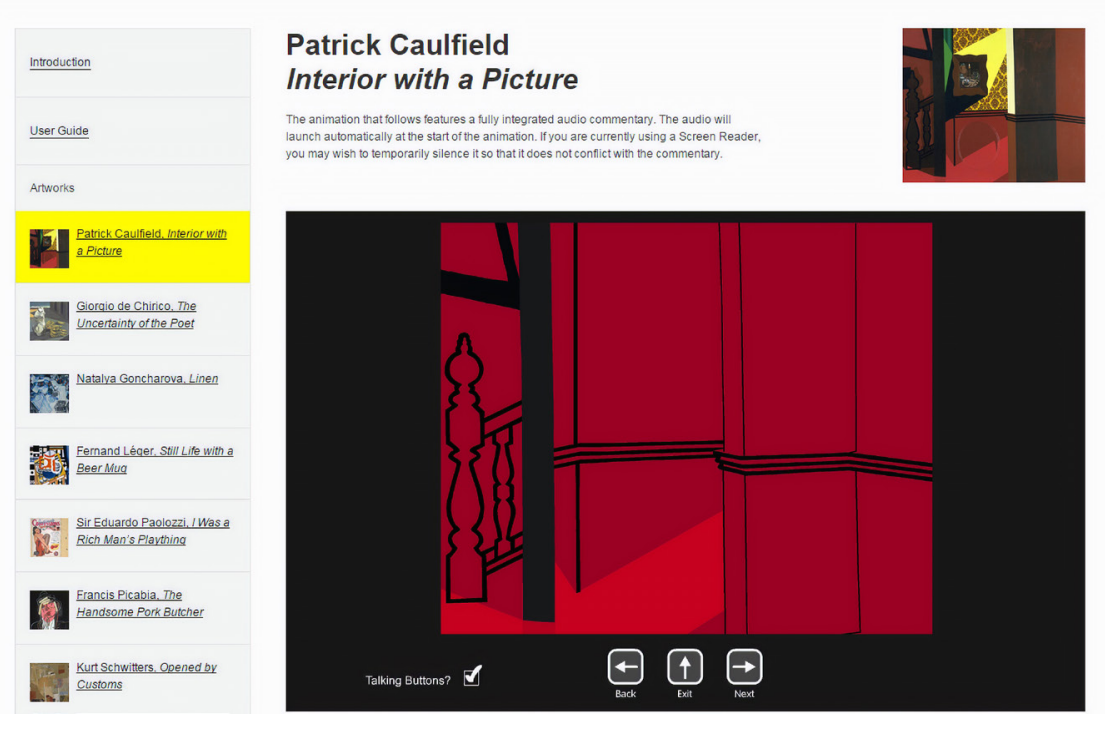

Figura 10 - Recurso de animação e áudio da obra Interior with a Picture - Patrick Caulfield, 1985, 2018. Site Imap.

Em outro contexto, destaca-se o projeto digital iMap, desenvolvido inicialmente como complemento da exposição Matisse e Picasso, realizada em 2002 pela Tate Modern. Na primeira fase do projeto, foram trabalhadas quatro obras de Matisse e quatro de Picasso. Em um segundo momento, foram exploradas seis obras de distintos artistas do século XX, todas pertencentes ao acervo da Tate. $O$ site, que recebeu um prêmio por sua acessibilidade, oferece distintas ferramentas para que o usuário tenha acesso à descrição detalhada e às informações relacionadas à obra. Os recursos oferecidos pelo site incluem 
47. Cf. Flor (2009).

48. Cf. W3C (2016).

textos, áudio acompanhado de animação e desenhos que podem ser impressos em relevo. A ferramenta de animação é controlada pelo usuário, que pode acompanhar passo a passo, por áudio e visualmente, a constituição da obra: cada elemento é adicionado e comentado à medida que o usuário utiliza a seta para prosseguir. Em seguida, ilustramos a utilização do recurso de animação e áudio na obra de Patrick Caulfield: na parte superior da imagem (figura 10), a apresentação da pintura original com todos os elementos e, abaixo, a animação que gradativamente adiciona os elementos e constitui o quadro quando o usuário pressiona a tecla para prosseguir.

Alternativa para conteúdo multimídia: a descrição em vídeos tem a função de contemplar as cenas visuais que não são transmitidas pelo diálogo ${ }^{47}$ ou perceptíveis através do som. Nesse sentido, é necessário que os conteúdos imagéticos da multimídia sejam transcritos ou reproduzidos através de áudio. A técnica mais comum para implementação da audiodescrição corresponde à sua incorporação no próprio vídeo durante os seus intervalos. Contudo, quando as pausas não são suficientes, recomenda-se que sejam oferecidas faixas de áudio estendidas. Essas faixas de descrição, com tempo de duração equivalente ao vídeo, podem ser disponibilizadas na página em que se encontra a multimídia ou em outra, por meio de um link que redirecione o usuário. ${ }^{48}$

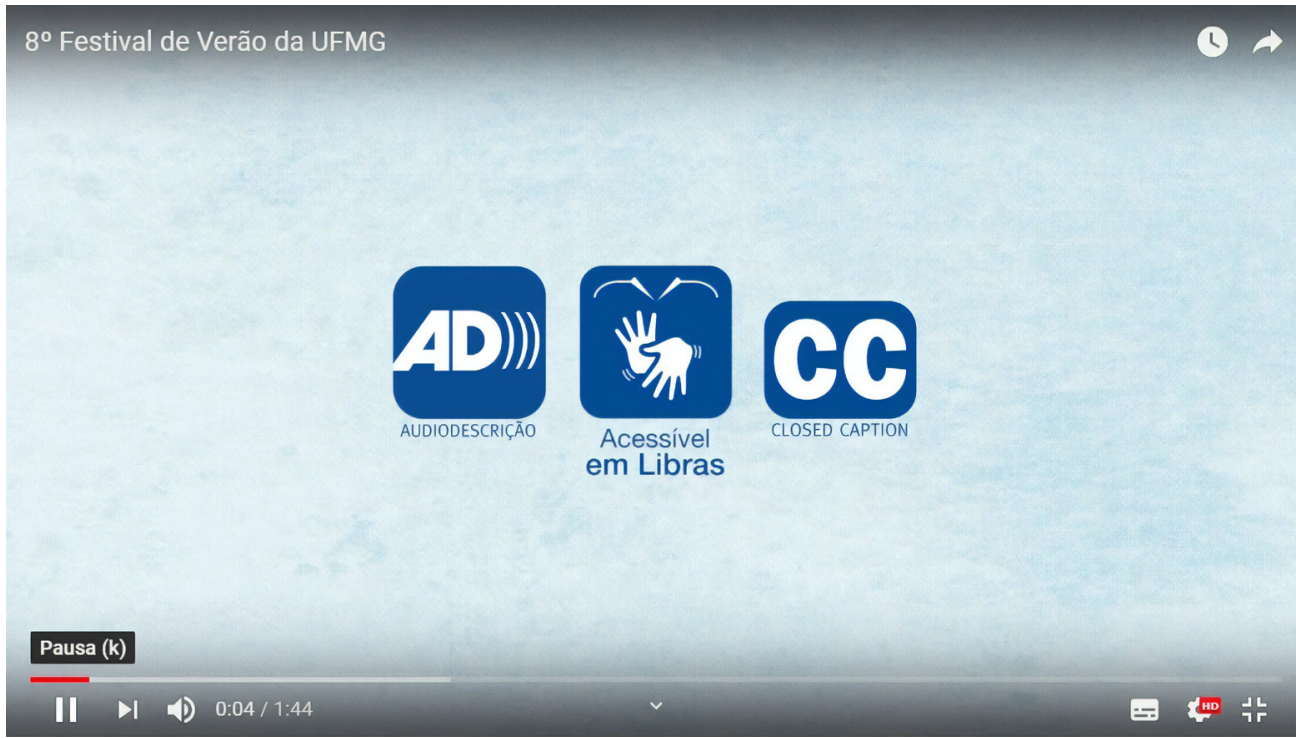

Figura 11 - Vídeo com audiodescrição, acessível em libras e com legenda - Divulgação do Festival de Verão da UFMG, 2018. Canal do YouTube: NCA CEDECOM UFMG. 
Como sintetizado no gráfico 4, quatro dos cinco participantes da pesquisa assinalaram que a ausência de descrição nos vídeos dificulta a compreensão de algumas informações disponibilizadas no site do MAO. A avaliação da ferramenta HERA não detectou a utilização de arquivos multimídias no site. Contudo, foi observado que o site faz a utilização de links para indicação de vídeos pertencentes a outras páginas na internet. Geralmente são reportagens relacionadas ao museu, destacando a exposição e seus eventos. No site há a introdução sobre conteúdo do vídeo, mas a multimídia não apresenta audiodescrição nem transcrição como alternativas. Uma das indicações do site do MAO diz respeito à matéria realizada por uma emissora brasileira sobre os dez anos do Museu de Artes e Ofícios. ${ }^{49}$

A imagem (figura 11) acima ilustra a utilização de audiodescrição sincronizada à multimídia. A imagem corresponde a um vídeo produzido pelo Núcleo de Comunicação e Acessibilidade da UFMG-NCA para divulgação do $8^{\circ}$ Festival de Verão da UFMG. O vídeo não apenas possui audiodescrição, mas também é acessível em libras e tem legenda, possibilitando o acesso à diversidade do público.

Facilidade visual e auditiva de distinção de conteúdos: se um conteúdo de áudio tocar automaticamente acima de três segundos em uma página, ele pode coincidir com o som do leitor de tela, interferindo na compreensão das informações e concentração do usuário. Portanto, é importante que haja um mecanismo para interrompê-lo ou pausá-lo. ${ }^{50}$ Nessa situação, as técnicas indicadas pelo W3C ${ }^{51}$ dizem respeito ao uso de um recurso que providencie o desligamento automático do áudio quando for detectada a utilização de tecnologia assistiva, ${ }^{52}$ como os leitores de tela, ou caso sejam disponibilizados controles no início da página, para que o usuário tenha a possibilidade de desativar o áudio. As revisões automática e manual não detectaram a utilização de áudios na página do Museu de Artes e Ofícios, portanto essa diretriz de acessibilidade não se aplica ao estudo. Em todo caso, geralmente as páginas da internet apresentam eficiência com relação a essa recomendação, tendo em vista, principalmente, que optam pela disponibilização de áudios que possuem controles integrados (figura 12).

Alguns dados levantados através do questionário aplicado aos participantes da pesquisa foram discutidos neste subtítulo, tendo em vista as diretrizes de acessibilidade que foram desenvolvidas com base no princípio que orienta que os sites devem disponibilizar seu conteúdo de forma perceptível para facilitar a navegação dos visitantes à página. Serão abordados, no próximo subtítulo, os demais resultados do estudo, destacando as diretrizes de acessibilidade desenvolvidas a partir dos princípios que dizem que os conteúdos dos sites devem ser operáveis e compreensíveis aos usuários.
49. Página do MAO que indica link de vídeo sobre a matéria realizada por emissora brasileira a respeito dos 10 anos do museu. Museu de Artes... (2013b).

50. Cf. Flor (2009).

51. Cf. W3C (2017).

52. O termo "Tecnologia Assistiva" é empregado para designar os recursos, mecanismos e serviços que objetivam aprimorar e dar suporte às pessoas com deficiência 
ESTUDO DE CASO: ANÁLISE DAS DIRETRIZES DE ACESSIBILIDADE INSPIRADAS NO PRINCÍPIO OPERÁVEL

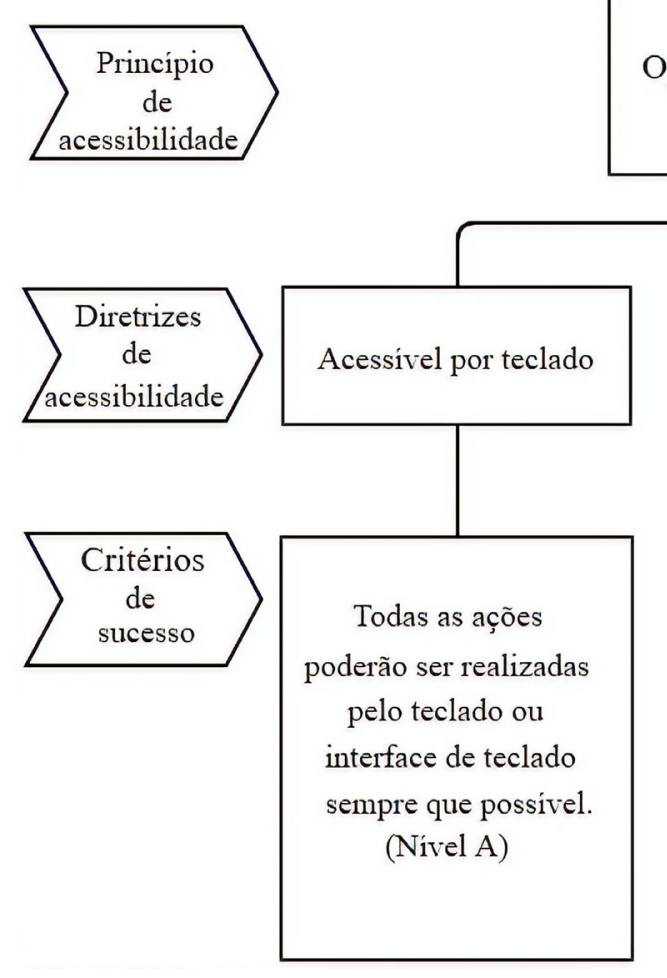

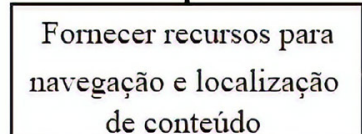
de conteúdo

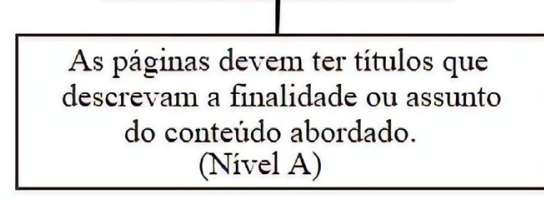

Fornecer links com textos que identifiquem seus propósitos. (Nivel A)

Disponibilizar informações sobre a localização do usuário em um conjunto de páginas.

(Nivel AAA)

Figura 13 - Diretrizes de Acessibilidade baseadas no Princípio Perceptível, 2017. Elaboração própria, a partir do WCAG 2.0 (W3C, 2008).

Acessível pelo teclado: essa diretriz diz respeito à possibilidade de que as funções realizadas pelo mouse sejam também executadas por meio de um teclado ou interface de teclado. A expressão interface de teclado é empregada 
para definir os dispositivos ou aplicativos que atuem como teclado, incluindo os teclados virtuais presentes em celulares e telas de computadores, softwares de entrada de voz ou outras alternativas. $\bigcirc$ mouse não é uma opção recomendada para pessoas com deficiência visual ou motora, considerando que, nesses casos, as atividades realizadas por essa ferramenta são dificultadas pela impossibilidade de visualizar, localizar e controlar o cursor nas páginas. Portanto, para facilitar a navegação é recomendado que as ações realizadas pelo mouse possam também a ser executadas com acionamento de uma tecla ou um conjunto de teclas $^{53}$. Segundo a avaliação da ferramenta HERA, o site do MAO não proporciona atalhos de teclado. Na página também não há indicações de que tal recurso foi disponibilizado. Portanto, os participantes da pesquisa não utilizaram outras teclas de atalho que não fossem as determinadas pelos leitores de tela durante a navegação pelo site do Museu de Artes e Ofícios.

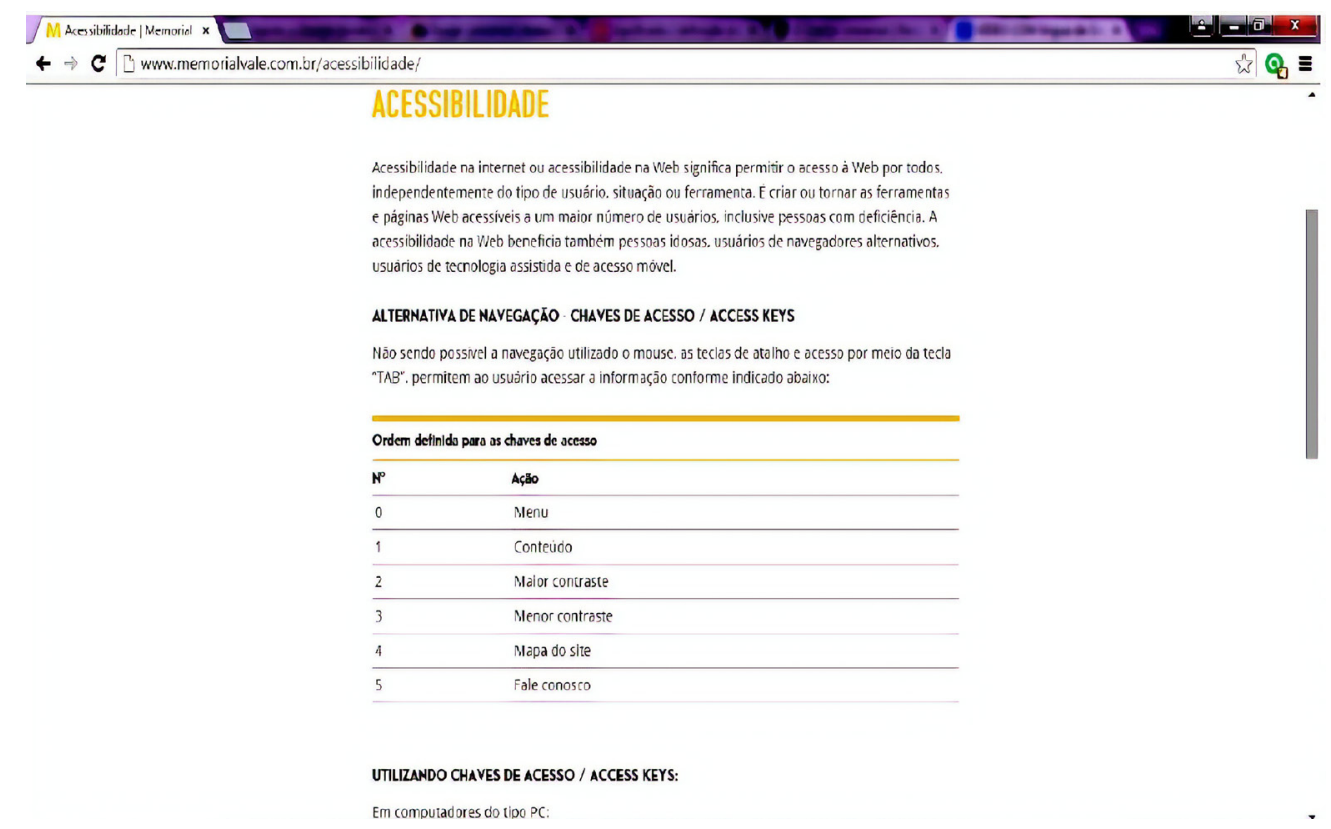

na realização das atividades. Cf. Freire (2008).

Figura 14 - Texto sobre recursos de acessibilidade em site, 2018. Página do Memorial Minas Gerais Vale.

É possível ilustrar a aplicação dessa diretriz com a imagem (figura 14) do site do Memorial Minas Gerais Vale que, em uma de suas páginas, discorre sobre a relevância da acessibilidade na internet para atender o público em sua diversidade e apresenta as teclas como alternativa caso não seja possível utilizar - mouse. As teclas de atalho possibilitam a realização de atividades como o acesso ao menu, ao mapa do site, a opção "fale conosco" e aos demais conteúdos. 
53. Cf. W3C (2016).

54. Ibid.

Também é possível a mudança de contraste através da combinação de teclas. Sob essa perspectiva, o site do memorial demonstra a relevância do oferecimento de alternativas para a realização de operações, mas também evidencia a importância de disponibilizar informações sobre a utilização do recurso para que os visitantes do site tenham ciência de que ele existe e de como podem utilizá-lo.

Fornecer recursos para navegação e localização de conteúdos: é importante que os visitantes de um site tenham a percepção de onde eles estão e, diante das possibilidades oferecidas, possam eleger seu destino. Uma página acessível é também aquela que otimiza o tempo do usuário, evitando sua exaustão física e mental durante a busca pelas informações de seu interesse e pelos recursos que ele precisa utilizar. Os critérios de sucesso dessa diretriz têm o objetivo de facilitar a navegação na página, tendo em vista a utilização de itens fundamentais para identificação e localização dos conteúdos. ${ }^{54}$

Como mencionado anteriormente, o questionário aplicado aos participantes do estudo é divido em três blocos de questões, sendo o último bloco destinado a verificar, principalmente, como eles avaliam a acessibilidade do site do Museu de Artes e Ofícios. Com o fim de não interferir na resposta da primeira pergunta desse bloco, os participantes não receberam, inicialmente, a informação sobre o nome da instituição que foi escolhida para o estudo, apenas sabiam que se tratava de um museu localizado no centro de Belo Horizonte. A visita ao site do museu ocorreria à medida que os participantes acessassem um link disponibilizado no próprio questionário. Em seguida, eles foram questionados se era possível identificar o nome da instituição do site que estariam visitando apenas com o link disponibilizado. Essa pergunta foi elaborada a partir do critério de sucesso que sugere que a acessibilidade de um site também está relacionada ao fornecimento de links com textos que identifiquem seus propósitos. Quem faz uso dos leitores de tela tem a possibilidade de pressionar a tecla Tab para navegar entre os links disponibilizados na página. Caso o link não tenha um texto claro, a pessoa não poderá identificar qual será seu próximo destino, ou seja, para qual página será redirecionado. São links com textos como: "clique aqui", "saiba mais", "mais detalhes". ${ }^{55}$

O texto do link para acessar o site do Museu de Artes e Ofícios corresponde a: http://www.mao.org.br. Como ilustrado no gráfico 2, apenas uma das participantes da pesquisa assinalou não ser possível identificar a instituição que tem domínio sobre o site que estava sendo visitado apenas com o link disponibilizado no questionário. Tendo em vista que o link está de acordo com as recomendações de acessibilidade, pois incorpora o nome da instituição em seu texto, foram levantadas duas hipóteses que poderiam justificar a não identificação do museu pela participante da pesquisa: é possível que ela não conheça o Museu de Artes e Ofícios ou não o 
reconheça pela sigla MAO. A primeira hipótese foi descartada ao analisar outra resposta da jovem, que afirmou já ter visitado a instituição em uma questão aberta.

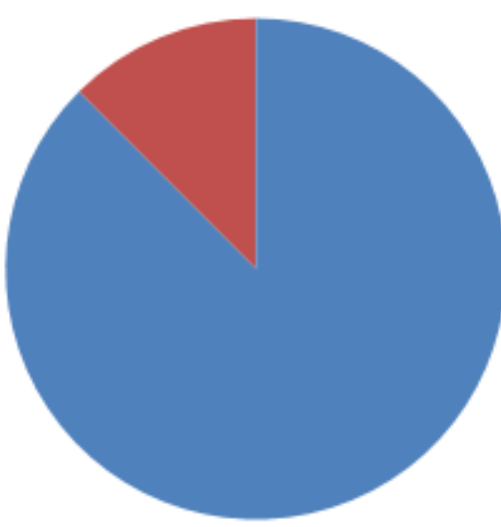

Sim, identifiquei o nome do museu com facilidade

Não foi possível saber o nome do museu apenas com o link

Gráfico 2 - Identificação do museu através do link disponibilizado no questionário. Elaboração própria, com dados coletados através de aplicação do questionário.

Quanto aos links disponibilizados no site do $M A O$, a avaliação da ferramenta HERA fez um levantamento dos existentes na página, contudo indicou ser necessário uma análise manual para valorar se os seus textos são objetivos e claros. Segundo as instruções da ferramenta, após a leitura dos links e do conhecimento do destino de cada um, será possível chegar a um resultado. A maioria dos links utilizados redirecionam o visitante a outros ambientes da própria página do MAO (figura 15), mas também há aqueles, como os disponibilizados na página inicial, que encaminham o visitante para os sites de outras instituições, entre elas o Instituto Cultural Flávio Gutierrez (ICFG), o Museu do Oratório em Ouro Preto e o Museu de Tiradentes em Mariana (figura 16). Os textos dos links se mostraram satisfatórios, sendo possível identificar a página de encaminhamento quando lidos.

A clareza e a objetividade do texto são tão importantes para identificação dos links quanto para os títulos de uma página. Uma página intitulada de forma adequada possibilita que um conteúdo seja localizado com maior facilidade e tende a dar maior autonomia ao visitante, propiciando a eleição das informações de sua preferência. Além disso, auxilia na navegação das pessoas com deficiência visual que, ao utilizar os leitores de tela, podem distinguir os conteúdos de várias páginas que estejam abertas no mesmo período sem necessidade de recorrer ao texto de cada uma. ${ }^{56}$ A avaliação da HERA indica que as páginas do site do MAO estão intituladas e sugere que a eficiência dos títulos seja 
analisada manualmente, lendo-os e relacionando-os aos seus conteúdos. Os títulos presentes no site se mostraram sintéticos e objetivos, refletindo com clareza os assuntos a serem abordados, pois estão organizados nos menus e submenus da página. $\bigcirc$ menu "Conheça", por exemplo, é composto por textos com os títulos: História da Coleção, O Edifício e a Praça, Implantação do Museu, Acervo, Espaços, Biblioteca, Publicações e Visita Virtual.

\section{Acessibilidade}

http://wrww.mao.org.br/visite/acessibilidade/

\section{AGENDE SUA VISITA}

http://agendamento.mao.org.br/

\section{Aula de Museu}

http://www.mao.org.br/acao-educativa/aula-de-museu/

Figura 15 - Links utilizados no site do MAO na página intitulada Visitas Mediadas, 2018. Levantamento realizado pela ferramenta HERA.

$$
\begin{aligned}
& \text { <img alt="16801" > ICFG Criado em 1998, o ICFG jÄi ì } \\
& \text { http://www.icfg.org.br/ }
\end{aligned}
$$

\section{«img alt="16807" > Museu do OratẪ ${ }^{3}$ rio Em Ouro Preto http://www.museudooratorio.com.br/}

\section{<img alt="16813" > Museu de Sant'Ana Em Tiradentes - http://museudesantana.org.br/}

Figura 16 - Links utilizados no site do MAO na página inicial, 2018. Levantamento realizado pela ferramenta HERA

Duas questões do questionário aplicado durante a investigação foram elaboradas com o objetivo de verificar se os participantes da pesquisa conseguiram localizar e acessar os conteúdos do site do MAO, tendo em vista a distribuição dos conteúdos na página, o oferecimento de mecanismos de pesquisa e a disponibilização de textos claros para identificação dos links. Primeiramente, os participantes foram questionados se tiveram dificuldades para encontrar ou acessar algum conteúdo. Como 
ilustrado no gráfico 3, a maioria dos participantes não demonstrou ter enfrentado dificuldades durante a navegação, sendo que cinco deles assinalaram ter tido facilidade para localizar e acessar informações. Entre os cinco, um marcou outra opção, reiterando a não dificuldade em encontrar e ter acesso aos conteúdos. Essa última opção foi assinalada por mais uma pessoa. Os demais visitantes também marcaram mais de uma opção, totalizando, então, dois participantes que indicaram ter a localização e o acesso às informações dificultados tanto pela distribuição dos conteúdos na página quanto pela ausência de identificação da funcionalidade dos links.

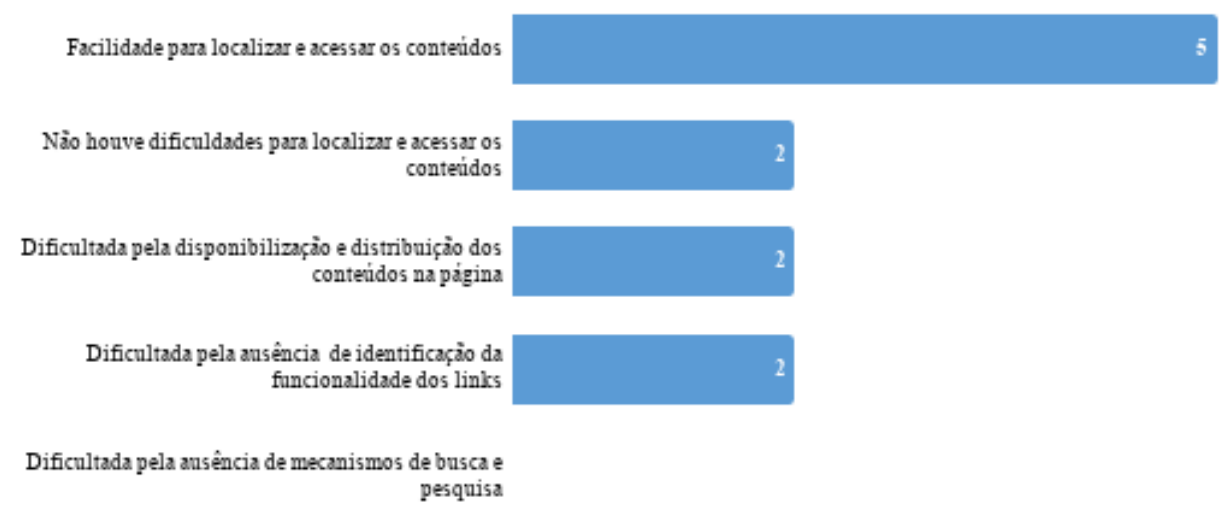

Número de participantes que assinalaram a opção. 0 grupo é constituido por 8 pessozs, que poderiam assinalar màis de uma opção.

Gráfico 3- Localização e acesso dos conteúdos do site. Elaboração própria, com dados coletados através de aplicação do questionário.

Como observado no gráfico 3, apesar de alguns participantes terem indicado dificuldade para encontrar e acessar os conteúdos do site do MAO, nenhum assinalou que a dificuldade resultava da ausência do mecanismo de busca para localização de conteúdo. Esse recurso é relevante para facilitar a navegação do visitante e, assim, evitar seu desgaste, pois possibilita que as informações sejam encontradas sem necessidade de percorrer todo o site. ${ }^{57}$ A avaliação da ferramenta HERA indicou a necessidade de uma análise manual para verificar se havia disponibilização do recurso de busca e em que nível ele poderia ser utilizado, tendo em vista que, quando se trata desse instrumento, podem ser ofertados recursos que realizem desde uma pesquisa simples até uma avançada. $\bigcirc$ mecanismo de busca do site do MAO pode ser localizado ao lado dos menus disponibilizados 
no início da página (figura 17) e propicia a realização de pesquisa simples, listando os resultados após a inserção do termo ou expressão pesquisada.

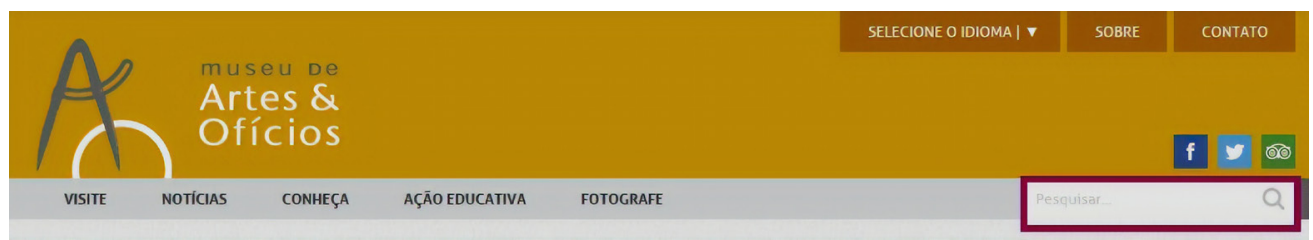

Figura 17 - Página inicial do MAO com destaque para o mecanismo de busca, 2018. Site do Museu de Artes e Ofícios.

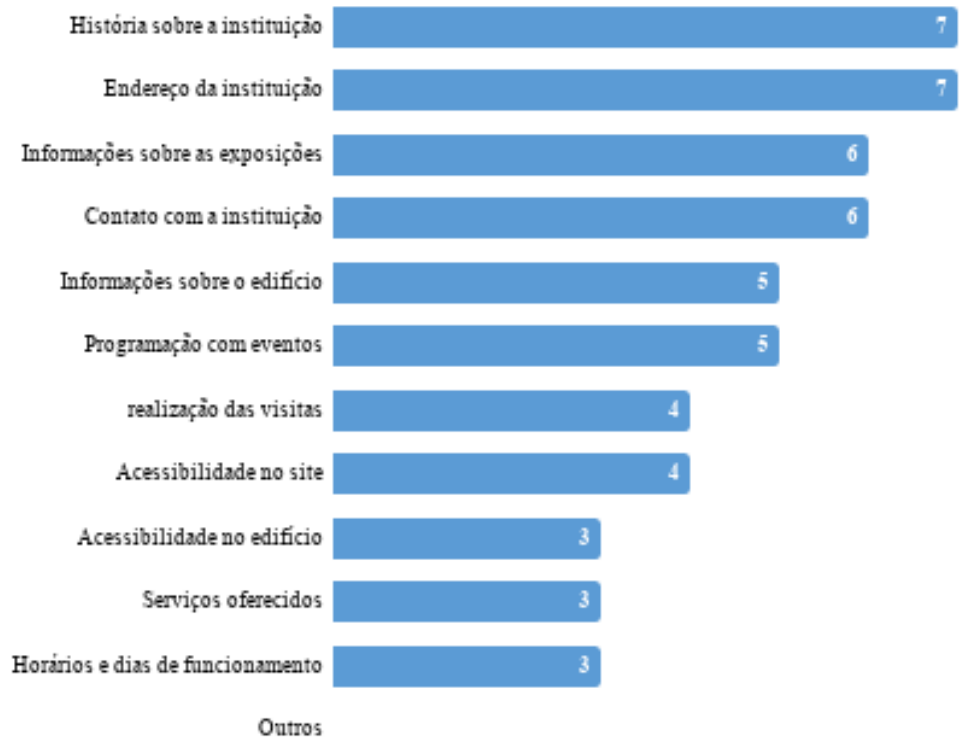

Número de participantes que assinalaram a opçào. 0 grupo é constituido por 8 pessoas, que poderiam assinalar mais de uma

Após veriticar se os participantes conseguiram localizar e acessar os conteúdos do site do Museu de Artes e Ofícios, se fazia necessário averiguar quais informações eles localizaram e tiveram acesso. Apesar de a maioria dos participantes terem indicado facilidade no acesso e localização das informações do site, menos da metade deles conseguiram localizar ou acessar informações fundamentais para realização de uma visita à instituição: dos oito participantes apenas três tiveram acesso a informações como acessibilidade no edifício, serviços oferecidos e horário de funcionamento. Por outro lado, as informações que 
apresentam o Museu foram acessadas pela maioria dos visitantes do site: sete das pessoas que responderam ao questionário disseram ter encontrado o conteúdo a respeito da história da instituição e o seu endereço. As informações sobre a exposição e o contato do MAO foram acessadas por seis participantes (gráfico 4).

Se o mecanismo de busca auxilia na localização dos conteúdos da página do MAO, os menus disponibilizados no início do site contribuem para que os visitantes tenham conhecimento dos conteúdos que o constituem, propiciando autonomia para que eles possam selecionar as informações de seu interesse. Contudo, a navegação no site pode ser aprimorada com o oferecimento de alternativas que sintetizem os conteúdos da página, tornando suas informações mais perceptíveis e acessíveis. $\bigcirc \mathrm{W} 3 \mathrm{C}^{58}$ recomenda que, para tal objetivo, seja feito o uso de mapas ou índices que descrevam e organizem os conteúdos de um site. Existem vários tipos de mapas, sendo que o mais simples e recorrente nas páginas da internet consiste em uma estrutura que apresenta links para cada seção ou tópicos de um site. Para ilustrar, evidenciamos o mapa de navegação utilizado no site do Espaço do Conhecimento UFMG (figura 18).

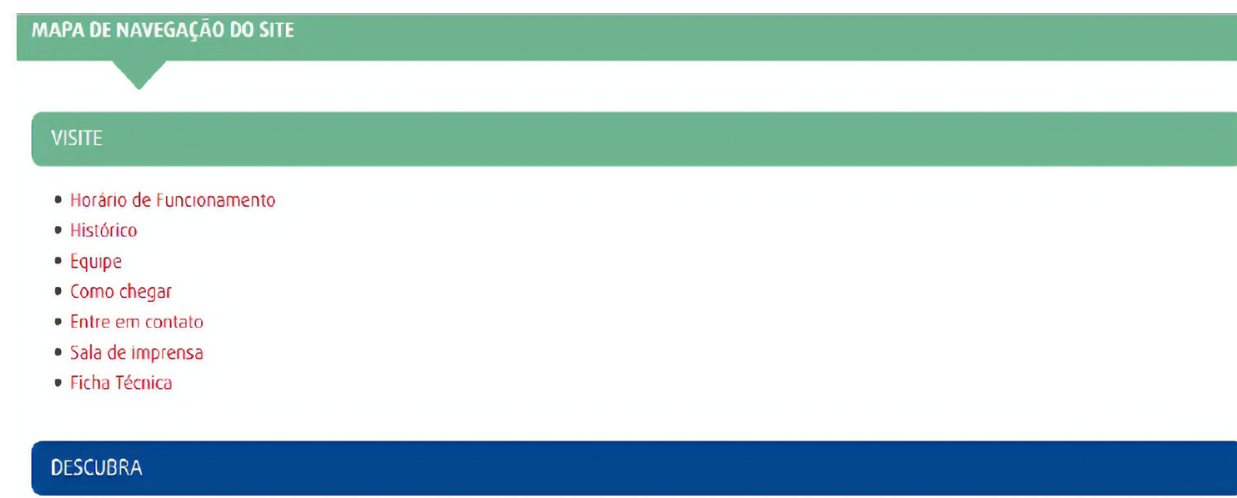

- Planetário

- Terraço Astronômico

- Exposiçōes

- Fachada Digital

- Livraria

- Cafeteria

Figura 18 - Mapa de navegação do site do Espaço do Conhecimento UFMG, 2018. Site do Espaço do Conhecimento UFMG.

O site do Espaço do Conhecimento UFMG evidencia a opção de navegação na página através do mapa ao utilizar símbolos que indicam que tanto esse recurso quanto a acessibilidade em libras estão disponíveis (figura 19). Sob essa perspectiva, ressalta-se novamente a relevância em oferecer o recurso e informar ao visitante da página a sua disponibilização. Lembrando que a disponibilização de símbolos e 
figuras deve ser acompanhada de alternativas textuais, possibilitando a identificação para as pessoas que fazem uso do leitor de tela.

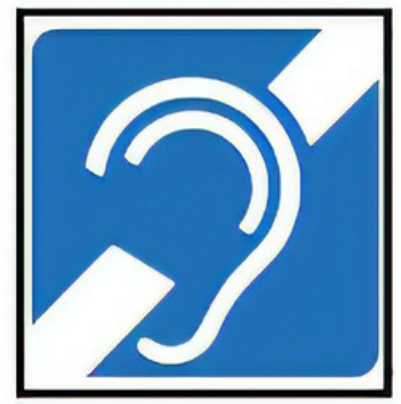

Figura 19 - Símbolos que indicam a utilização de mapa de navegação e acessibilidade em libras no site, 2018.

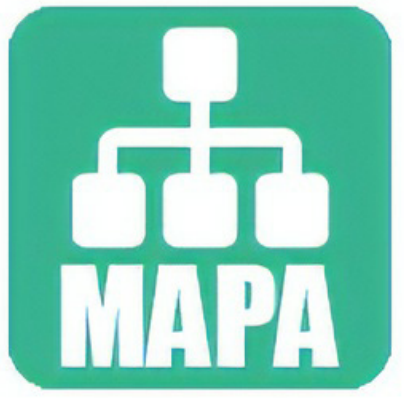
Site do Espaço do Conhecimento UFMG.

ESTUDO DE CASO: ANÁLISE DAS DIRETRIZES DE ACESSIBILIDADE INSPIRADAS NO PRINCÍPIO COMPREENSÍVEL

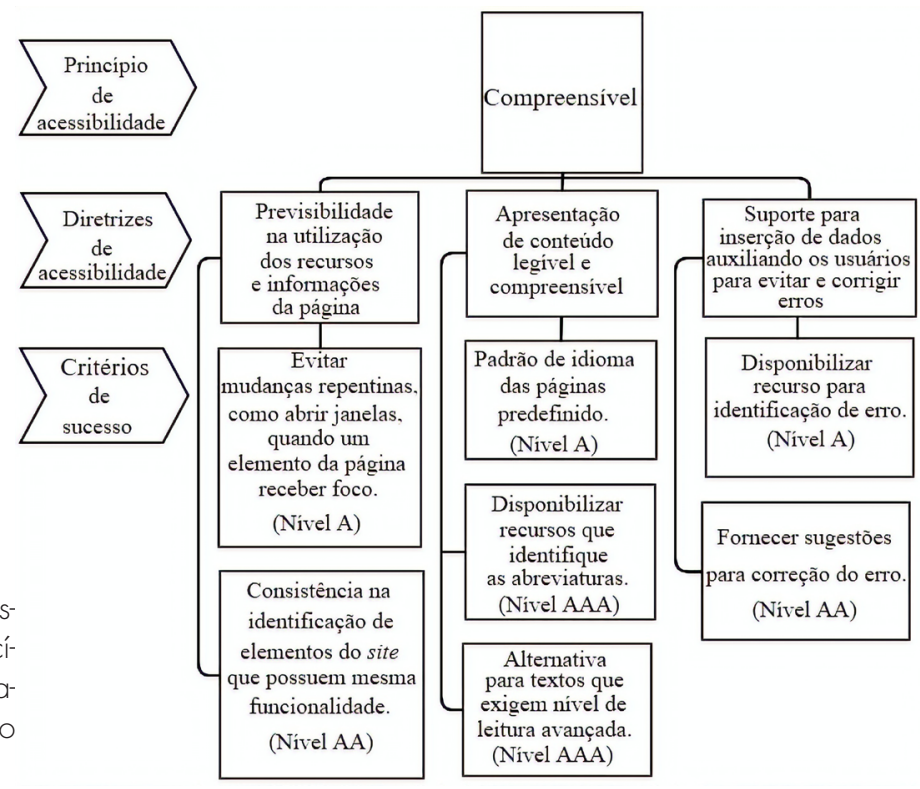


Previsibilidade na utilização dos recursos e informações da página: é importante que a funcionalidade dos recursos disponibilizados em um site seja previsível, tendo em vista que esse fator pode facilitar a operação e interação do visitante com os componentes da página, resultando na ampliação do acesso às informações. Sob essa perspectiva, um dos critérios de sucesso dessa diretriz diz respeito a evitar mudanças repentinas quando um elemento da página receber foco. A abertura de páginas e o envio de formulários, por exemplo, não devem ocorrer de forma automática apenas porque o componente recebeu foco. É necessário que as ações sejam executadas quando o componente tenha sido submetido a um clique ou sido pressionado através de controles do teclado ou mouse. As mudanças inesperadas podem desorientar e influenciar na concentração das pessoas durante a visita à página. ${ }^{59}$ A avaliação da ferramenta HERA não detectou o uso de recursos que ativassem automaticamente os componentes no site do $M A O$, assegurando aos visitantes o controle sobre as ações realizadas.

A previsibilidade de um site também é resultado da organização e representação dos conteúdos na página. Os recursos devem ser apresentados de forma consistente, deixando clara suas funcionalidades. A navegação pode se tornar confusa e ser dificultada com apresentação de itens que tenham a mesma função, mas que possuam rotulação diferenciada. $\bigcirc$ mesmo vale para mecanismos com funcionalidades distintas, mas com a mesma identificação. Quando se trata de ícones e figuras, a alternativa textual também deve ser consistente. Recomenda-se, ainda, que os componentes que estejam presentes durante toda navegação no site mantenham-se no lugar. $\bigcirc$ visitante tende a se familiarizar com a ordem estabelecida na página, tornando previsível a localização dos conteúdos. A ferramenta HERA orienta que, para verificação dessa recomendação, faz-se necessário observar se os recursos de navegação aparecem sempre posicionados no mesmo lugar e, no caso da utilização de ícones, analisar a consistência da identificação desses recursos. Os mecanismos de navegação, que são recorrentes durante toda visita ao site do MAO, posicionam-se no mesmo lugar em todas as seções acessadas, correspondem ao símbolo da instituição, aos menus, ao mecanismo de busca, à opção do idioma, ao contato e às redes sociais do museu que são representadas por meio de ícones. Esses elementos já foram apresentados anteriormente (figura 17).

No que se refere aos demais recursos de navegação do site, como ilustrado (figura 21), foi observado que alguns são identificados tanto textual quanto imageticamente: a ferramenta que possibilita que sejam baixados alguns arquivos da seção biblioteca, por exemplo, é identificada pelo termo "Download" e pelo ícone de um disquete. Ambos cumprem a mesma função, mas são alternativas que 
propiciam o acesso de um público mais amplo e diverso. Sendo o disquete um ícone comumente conhecido e geralmente utilizado para salvar documentos no computador, é possível que algumas pessoas compreendam a funcionalidade do recurso disponibilizado no site apenas ao observar esse item. Por outro lado, o texto se apresenta como alternativa importante para aqueles que não conseguiram compreender apenas com a figura utilizada ou para as pessoas com deficiência visual que não perceberiam o conteúdo imagético sem a alternativa de texto.

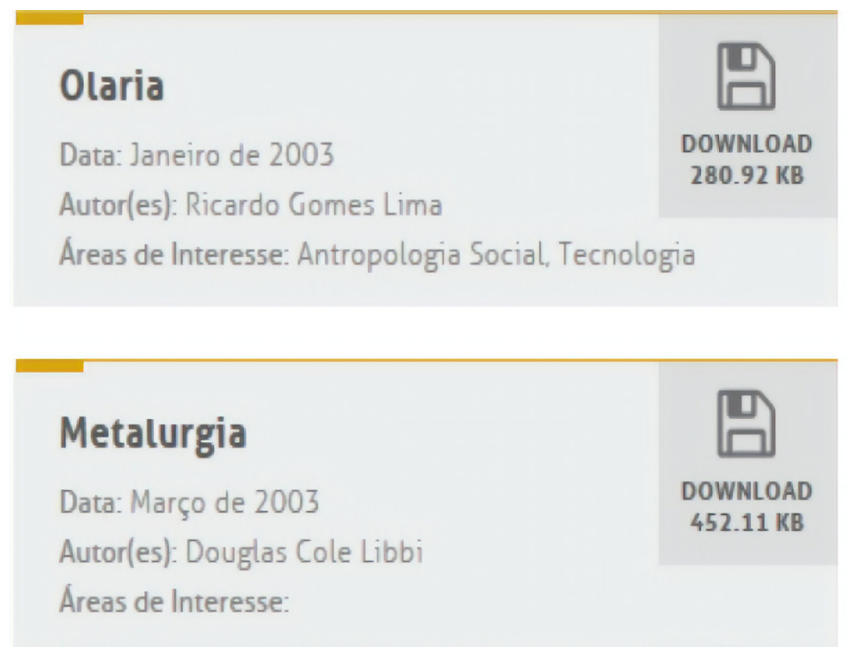

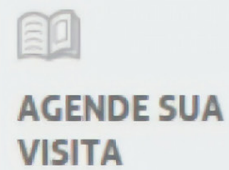

VISITA

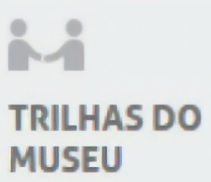

Figura 21 - ĺcones e alternativas de texto para identificação de recursos utilizados no site, 2018. Site do Museu de Artes e Ofício.

Apresentação de conteúdo legível e compreensível: a acessibilidade de um site perpassa tanto pelo acesso aos conteúdos quanto pela sua compreensão. Consiste em propiciar a leitura do texto pelos visitantes da página e pelas tecnologias de assistência, garantindo que as informações necessárias para compreensão estejam disponíveis. Sob essa perspectiva, é importante que, durante a elaboração do conteúdo disponibilizado no site, sejam considerados elementos como o idioma em que o texto será redigido, a linguagem empregada e as regras de ortografia e gramática. A identificação prévia do idioma da página contribui para a pronúncia correta das palavras pelos visitantes e pelos leitores de tela que, ao detectar o idioma utilizado, podem carregar as regras para pronúncia adequada. ${ }^{60} \mathrm{~A}$ ferramenta HERA verificou se havia identificação do idioma principal da página do MAO e concluiu que o idioma é indicado pelo código "pt-BR", sinalizando que o site está de acordo com a orientação de acessibilidade. 
Outro aspecto que deve ser ponderado para otimizar a compreensão dos 60. Ibid. textos disponibilizados no site diz respeito à utilização de estratégias e recursos 61. Ibid. que identifiquem as abreviaturas apresentadas para o visitante durante sua navegação na página. Vale lembrar que, mesmo que uma abreviatura seja comumente conhecida, ela pode ter diferentes significados dependendo do contexto em que for empregada. Uma interpretação errônea ou desconhecimento de determinada sigla pode interferir na compreensão do texto. Há a possibilidade de que a definição de uma abreviatura seja fornecida no próprio texto, antes ou depois de seu uso, mas também disponibilizando a abreviatura na forma de link para que seja possível acessar sua definição na mesma página ou em uma página diferente. Esses recursos também poderão ser empregados para explicar palavras incomuns, como as expressões de outros idiomas. ${ }^{61}$ Segundo a ferramenta HERA, é necessário observar se a abreviatura é especificada por extenso na primeira vez em que aparece na página. Após a leitura dos textos disponibilizados no site do MAO, chegou-se à conclusão de que a página fornece a identificação das siglas nas próprias publicações em que aparecem e, portanto, está de acordo com essa recomendação de acessibilidade. O texto da seção "Conheça", que introduz a história da coleção, por exemplo, inicialmente inclui por extenso o nome do Museu de Artes e Ofícios seguido pela sigla MAO, que é apresentada entre parênteses. Posteriormente, cita a sigla IPHAN e, depois de um sinal de travessão, indica o nome do Instituto do Patrimônio Histórico e Artístico Nacional.

Em casos de textos que exijam uma capacidade de leitura mais avançada que o nível de educação secundário inferior, correspondente no Brasil aos últimos anos do ensino fundamental, é recomendada a disponibilização de um conteúdo complementar ou de uma versão que não exija leitura mais avançada que esse nível. ${ }^{62}$ Em suma, é relevante que o texto publicado no site seja prático, claro e acessível à diversidade do público.

Com o fim de perceber qual a relação que os participantes da pesquisa estabeleceram com os textos publicados no site do MAO, foram elaboradas questões sobre a compreensão de alguns dos conteúdos. Quando questionados se foi possível compreender a história do museu com o texto disponibilizado no site, sete dos participantes assinalaram que o texto é de fácil compreensão e um indicou que não havia publicações sobre o tema (gráfico 5). Nenhum deles assinalou a opção de que o texto era de difícil compreensão ou a alternativa de que houve dificuldade para compreender algumas palavras do texto. 


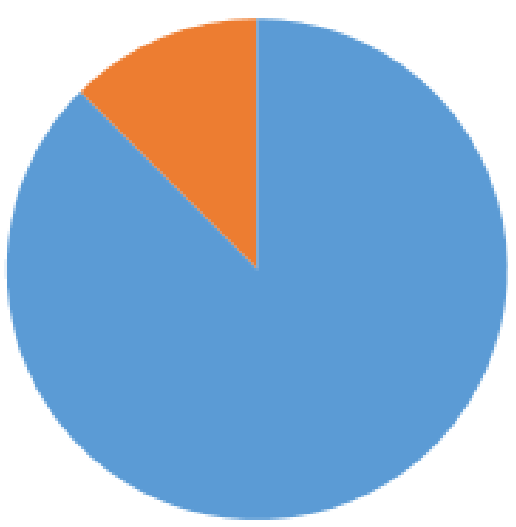

Sim, o texto é de fácil compreensão

Não havia texto sobre a história da instituição no site

Gráfico 5 - Compreensão sobre a história do museu com o texto disponibilizado no site. Elaboração própria, com dados coletados através de aplicação do questionário.

Os participantes do estudo também foram questionados sobre a possibilidade de conhecer a exposição do MAO por meio do texto disponibilizado no site. Entre os oito visitantes da página, seis sinalizaram ser possível conhecer a exposição, pois o texto era de fácil compreensão; um indicou que não havia publicações sobre o tema e o outro não respondeu à pergunta, deixando-a em branco (gráfico 6). Como na questão anterior, nenhum deles assinalou a opção de que o texto era de difícil compreensão ou a alternativa de que houve dificuldade para compreender algumas palavras do texto.

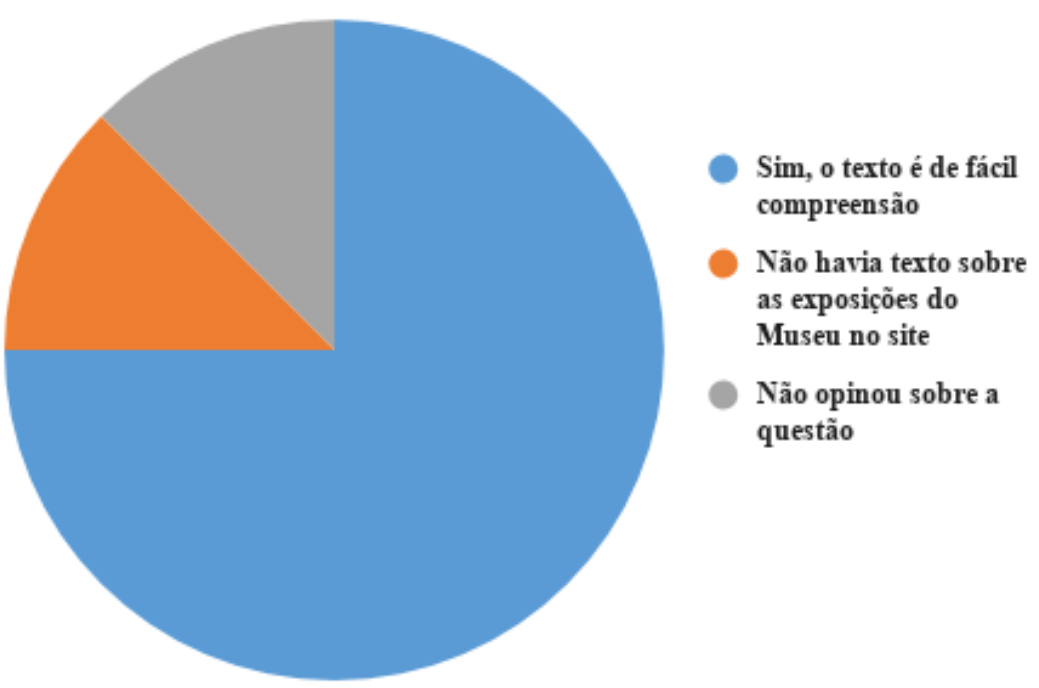

Gráfico 6 - Possibilidade de conhecer as exposições do museu com o texto disponibilizado no site. Elaboração própria, com dados coletados através de aplicação do questionário. 
Suporte para inserção de dados, auxiliando os usuários para evitar e corrigir erros: essa recomendação de acessibilidade tem o objetivo de orientar e 63. Ibid. oferecer assistência ao visitante de um site em caso de erros durante a inserção de dados, algo que geralmente pode ocorrer nos casos em que há necessidade de preenchimento de campos, como em formulários e mecanismos de busca. A mensagem de erro deve ser a mais objetiva possível, tendo em vista que o visitante pode desistir de realizar a ação se não compreender a razão que impossibilita sua realização. As pessoas que utilizam leitores de tela, por exemplo, não estarão cientes de que ocorreu um erro até que os indicadores sejam encontrados. A acessibilidade, no que se refere a esse aspecto, poderá ainda ser otimizada se, além do oferecimento do suporte de detecção de erro, seja disponibilizado recurso de ajuda para a correção. ${ }^{63}$

Segundo a ferramenta HERA, é preciso utilizar os recursos da página e observar sua funcionalidade, analisando se são oferecidos mecanismos para inserção de dados e em que medidas esses mecanismos assistem o visitante nas ações que ele pretende realizar. Os recursos que serão analisados no site do Museu de Artes e Ofícios correspondem ao mecanismo de busca, já apresentado anteriormente, e a um formulário de cadastramento para agendamento de visita mediada à instituição que está disponível no site na seção "Planeje sua visita". No que diz respeito ao formulário disponibilizado no site do MAO, foi possível perceber que seu envio é malsucedido quando alguns campos, considerados obrigatórios, não são preenchidos ou há inconsistência de informações. No início da página será apresentada uma mensagem sobre os erros que ocorreram: nesse caso, a ausência de algumas informações, como o contato e a formação de quem está preenchendo o formulário e a diferença de caracteres informados para a senha e para sua confirmação (figura 22).

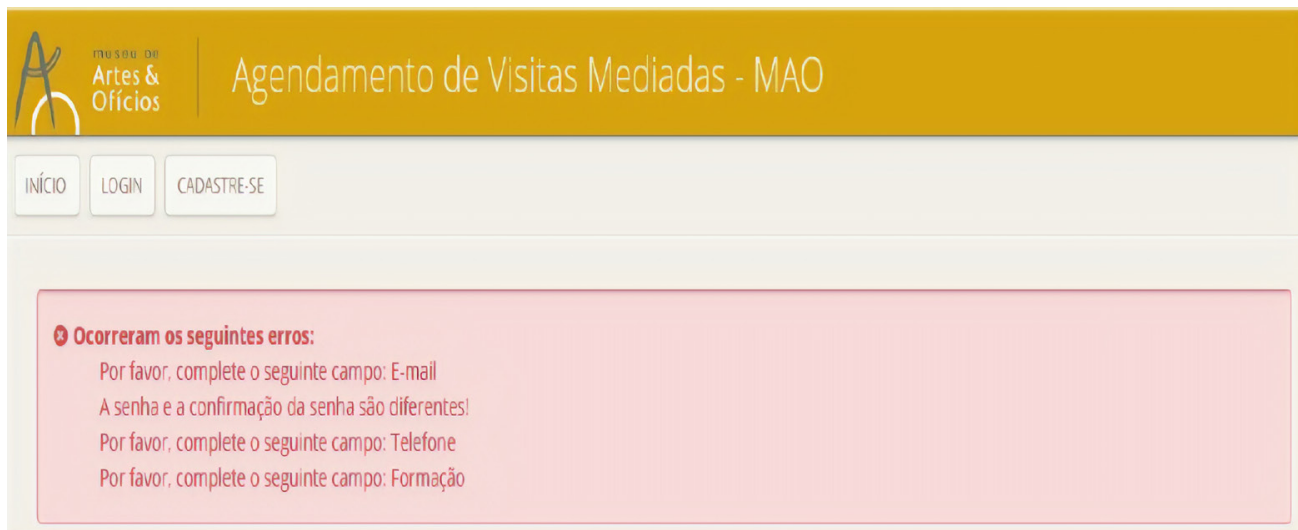

Figura 22 - Análise sobre o suporte para inserção de dados no formulário disponibilizado pelo site do MAO, 2018. Site do Museu de Artes e Ofícios. 
Quanto à investigação do mecanismo de busca diante da inserção de uma palavra com grafia errada, o site apresenta a mensagem de que é necessário redefinir ou alterar a busca por novos resultados. Em seguida, também há frases que dizem que a pesquisa não retornou o resultado e que é preciso tentar outras palavras (figura 23).

RESULTADOS DA PESQUISA

O RESULTADOS PARA:

esposiçào

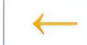

REFINE OU ALTERE SUA BUSCA PARA NOVOS RESULTADOS

Ops, infelizmente sua pesquiso næ̊o retornou nenhum resultado Tente pesquisar por outras palavras.

Figura 23 - Análise sobre o suporte para inserção de dados do mecanismo de busca do site do MAO, 2018. Site do Museu de Artes e Ofícios.

\section{CONSIDERAÇÕES FINAIS}

Retomando o objetivo de averiguar como se configura a acessibilidade nos sites das instituições museológicas, a investigação no site do Museu de Artes e Ofícios constatou que há aspectos em que a página está de acordo com as recomendações de acessibilidade, mas também outros que poderiam ser aprimorados. $\bigcirc$ site do MAO se mostrou eficiente ao oferecer links funcionais, com textos que descrevem sua finalidade e com seções com títulos sintéticos e objetivos. Apresentou bom desempenho no que tange à consistência na navegação, pois os itens que são recorrentes na mudança de seção não alteram sua posição, do mesmo modo que existe igual identificação para recursos com a mesma função. Outro ponto positivo foi quanto à prévia identificação do idioma da página, que tende a contribuir para a pronúncia correta das palavras pelos visitantes e pelos leitores de tela.

O site teve desempenho médio em relação à facilidade da localização dos conteúdos. Apesar do oferecimento do mecanismo de busca e da maioria dos participantes terem indicado facilidade no acesso e localização das informações, menos da metade deles conseguiram localizar ou acessar informações fundamentais para realização de uma visita à instituição: dos oito participantes, apenas três assinalaram que tiveram acesso a informações como acessibilidade no edifício, serviços oferecidos e horário de funcionamento. A indicação para otimizar e facilitar a localização dos conteúdos, segundo as 
diretrizes do W3C, diz respeito a disponibilizar um mapa ou índice que descreva e organize, hierarquicamente, os conteúdos de um site.

site ainda não supriu as expectativas com relação ao oferecimento de textos alternativos para os conteúdos imagéticos. Apesar de fazer uso do atributo alt, disponibilizando uma alternativa textual adequada para muitas imagens, foram encontrados alguns textos alternativos que não são claros, dificultando a identificação do conteúdo imagético. A página também não supriu as expectativas quanto ao oferecimento de atalhos de teclado para realização de funções que são executadas pelo mouse. O recurso não foi identificado pela ferramenta HERA e no site não há, também, indicações de que seja possível navegar através do teclado.

presente estudo trouxe alguns dados relevantes, mas também suscitou indagações que abriram possibilidades para realização de novas investigações que poderiam esclarecer as questões suscitadas. Ainda que alguns recursos oferecidos pelo site do MAO estejam de acordo com as orientações de acessibilidade, não há indicativos de que esse tema seja uma das pautas do museu, ou seja, o site não disponibiliza nenhum texto que denote um esforço para tornar a página mais acessível ou demonstre que há recursos que são oferecidos com esse fim.

Se a ampliação da rede mundial de computadores ocorreu na década de 1990, podemos dizer que a apropriação da internet pelos museus é algo razoavelmente recente. E, como foi possível observar, a acessibilidade nos sites também o é. Mesmo que o MAO faça parte do pequeno grupo museológico notável pelas ações de acessibilidade na infraestrutura e pela demonstração de aproximação do conhecimento sobre o tema, seria essa a justificativa para que ainda não tenha dado a devida atenção para a acessibilidade no site? Ou será que há consciência sobre a questão da acessibilidade na internet e esforços para atender a algumas orientações, mas ainda não foram evidenciados na página? A compreensão de que o Museu de Artes e Ofícios tem consciência da relevância do tema e a pretensão de ampliar a acessibilidade no site através da aplicação das diretrizes implica no desenvolvimento de um estudo que envolva os desenvolvedores da página e representantes da instituição. 


\section{REFERÊNCIAS}

LIVROS, ARTIGOS E TESES

ALVES, Magda. Como escrever teses e monografias: um roteiro passo a passo. $2^{\text {a }}$ ed. Rio de Janeiro: Campus, 2007.

AMIRALIAN, Maria Lúcia Toledo Moraes. Sou cego ou enxergo? As questões da baixa visão. Revista Educar. Curitiba, n. 23, p. 15-28, 2004.

AURÉLIO, Buarque de Holanda Ferreira. O minidicionário da língua portuguesa. $4^{\mathrm{a}}$ ed. revista e ampliada. $7^{\mathrm{a}}$ impr. Rio de Janeiro: Nova Fronteira, 2002.

BRAGA, Jezulino Mendes. Professores de História em cenários de experiência. 2014. Tese (Doutorado em Educação) - Universidade Federal de Minas Gerais, Belo Horizonte, 2014.

CAMBIAGHI, Silvana. Desenho universal: métodos e técnicas para arquitetos e urbanistas. São Paulo: Senac, 2007.

CARVAlHO, Rosane Maria Rocha. Comunicação e informação de museus na internet e o visitante virtual. Revista Eletrônica do Programa de Pós-Graduação em Museologia e Patrimônio. v. 1, n. 1, p. 83-93, jul/dez de 2008.

CASTELLS, Manuel. A sociedade em rede. São Paulo: Paz e Terra, 1999.

CASTELLS, Manuel. Museus na era da informação: conectores culturais de tempo e espaço. 2011. In: BARRANHA, Helena; MARTINS, Susana S.; RIBEIRO, António Pinto. Museus sem lugar ensaios: manifestos e diálogos em rede. Lisboa: Unplace, 2015.

CATEL, Pierre. Museu de Artes e Ofícios, Belo Horizonte: afinal, como nascem os museus? (Entrevista concedida a Luciana Sepúlveda Köptcke). História, Ciências, Saúde, Manguinhos, v. 12 (suplemento), p. 323-38, 2005.

DELOCHE, Bernard. El Museo Virtual. Gijón: TREA, 2002.

FLOR, Carla da Silva. Diagnóstico da Acessibilidade dos principais museus virtuais disponíveis da internet. 2009. 129 f. Dissertação (Mestrado em Engenharia e Gestão do Conhecimento) - Universidade Federal de Santa Catarina, Florianópolis, 2009. 
FREIRE, André Pimenta. Acessibilidade no desenvolvimento de sistemas web: um estudo sobre o cenário brasileiro. 2008. Dissertação (Mestrado em Ciência da Computação e Matemática Computacional) - Universidade de São Paulo, São Carlos, 2008.

KASTRUP, V. Cegos e videntes se encontram no museu: da dicotomia à partilha dosensível. In: II Seminário Internacional Ciência e Museologia: Universo Imaginário, 2011, Belo Horizonte. Anais [...]. Belo Horizonte: ECI-UFMG, 2011. p. 87-97.

LARROSA BONDÍA, Jorge. Notas sobre a experiência e o saber de experiência. Tradução de João Wanderley Geraldi. Universidade Estadual de Campinas, Departamento de Linguística. Revista Brasileira de Educação, n. 19, p. 20-28, 2002.

LÉVY, Pierre. Cibercultura. Rio de Janeiro: Editora 34, 1999.

MIRANDA, Rose Moreira de. Informação e sites de museus de arte brasileiros: Representação no ciberespaço. 2001. Dissertação (Mestrado em Ciência da Informação) - IBICT, Programa de Pós-Graduação em Ciência da Informação; Escola de Comunicação, Universidade Federal do Rio de Janeiro, Rio de Janeiro, 2001.

NIELSEN, Jakob. Projetando websites. São Paulo: Campus, 2000.

ONU. Declaração Universal dos Direitos Humanos. Disponível em: <https://bit.ly/1CVqinH>. Acesso em: 10 set. 2017.

RAMOS, Francisco Régis Lopes. A danação do objeto: o museu no ensino de História. Chapecó: Argos, 2004.

ROCHA, Jánicy Aparecida Pereira; DUARTE, Adriana Bogliolo Sirihal. Diretrizes de acessibilidade web: um estudo comparativo entre as WCAG 2.0 e o e-MAG 3.0. Inclusão Social, Brasília, DF, v. 5 n. 2, p.73-86, jan./jun. 2012.

SASSAKI, Romeu Kazumi. Inclusão: acessibilidade no lazer, trabalho e educação. Revista Nacional de Reabilitação (Reação). São Paulo, Ano XII, p. 10-16, mar./abr. 2009.

SILVA, Fabricia de Oliveira; OLIVEIRA, Lívio Ramsés Ucrân de; MOURTHÉ, Naila Garcia. Quando os olhos não são a janela da alma. In: IV Seminário da Rede Informal de Museus e Centros Culturais. 2012, Belo Horizonte. Anais [...]. Belo Horizonte: Museu de Arte da Pampulha, 2012. 
SILVA, Míriam Célia Rodrigues; LOPES, José de Sousa Miguel. Em busca da inclusão digital e da acessibilidade nos processos educativos e nas reuniões nacionais e regionais da Anped. In: V Seminário Educação e Formação Humana: Desafios do Tempo Presente, 2017, Belo Horizonte. Anais eletrônicos[...]. Belo Horizonte: FAE - UEMG, 2017.

SILVA, Míriam Célia Rodrigues; LOPES, José de Sousa Miguel. Entre a Dimensão Educativa e o Design Universal: reflexões sobre a acessibilidade de sites de instituições culturais. In: XIII Seminário Nacional O Uno e o Diverso na Educação Escolar e XVI Semana da Pedagogia, 2016, Uberlândia. Anais eletrônicos [...]. Uberlândia: FAE -UFU, 2016. p. 1903-1918.

SOARES, Bruno C. Brulon; SCHEINER, Tereza C. M. A ascensão dos museus comunitários e os patrimônios 'comuns': um ensaio sobre a casa. FREIRE, Gustavo Henrique de Araújo (org.) E-book do Encontro Nacional da Associação Nacional de Pesquisa em Ciência da Informação. A responsabilidade social da ciência da Informação. João Pessoa: Ideia/Editora, 2009.

TEIXEIRA, Edson Sidnei Maciel; OKIMOTO, Maria Lucia Leite Ribeiro; HEEMANN, Adriano. Estudos em Design. Revista (on-line). Rio de Janeiro: v. 23, n. 2, p. 133-149, [2015].

VENTORINI, S. E. A experiência como fator determinante na representação espacial do deficiente visual. 2007. Dissertação (Mestrado em Geografia) - Universidade Estadual Paulista, Instituto de Geociências e Ciências Exatas, Rio Claro, 2007.

YIN, R. K. Estudo de caso: planejamento e métodos. Tradução: Daniel Grassi. 2. ed. Porto Alegre: Brookman, 2001.

LEGISLAÇÃO

BRASIL. Constituição (1988). Constituição da República Federativa do Brasil. Brasília, DF: Senado Federal. 2004.

BRASIL. Decreto n. 5.626, de 22 de dezembro de 2004. Regulamenta as Leis n.10048, de 8 de novembro de 2000, que dá prioridade de atendimento às pessoas que especifica, e 10.098, de 19 de dezembro de 2000, que estabelece normas gerais e critérios básicos para a promoção da acessibilidade das pessoas portadoras de deficiência ou com mobilidade reduzida, e dá outras providencias. Diário Oficial [da] União, Brasília, DF, dez. 2004. Disponível em: <https://bit.ly/1rGGo0G>. Acesso em: 27 ago. 2017.

BRASIL. Lei $\mathrm{n}^{\circ}$. 10.048, de 08 de novembro de 2000a. Dá prioridade de atendimento às pessoas que especifica, e dá outras providências. Diário Oficial [da República Federativa do Brasil], Brasília. Disponível em: <https://bit.ly/2Yg8wOw>. Acesso em: 27 ago. 2017. 
BRASIL. Lei $\mathrm{n}^{\circ}$. 10.098, de 19 de dezembro de 2000b. Estabelece normas gerais e critérios básicos para a promoção da acessibilidade das pessoas portadoras de deficiência ou com mobilidade reduzida, e dá outras providências. Diário Oficial [da República Federativa do Brasil], Brasília. Disponível em: https://bit.ly/1eaSigz. Acesso em: 27 ago. 2017.

BRASIL. Lei $\mathrm{n}^{\circ}$. 11.904, de 14 de janeiro de 2009. Institui o Estatuto de Museus e dá outras providências. Diário Oficial [da República Federativa do Brasil], Brasília. Disponível em: <https://bit.ly/2FMdvSc>. Acesso em: 27 ago. 2017.

SITES

$8^{\circ}$ FESTIVAL DE VERÃO DA UFMG. 1 vídeo (1 min 44 segs.). Publicado pelo canal NCA CEDECOM UFMG. Disponível em: <https://bit.ly/2RAn211>. Acesso em: 14 jan. 2018

BRASIL.EMAG: Modelo de Acessibilidade em Governo Eletrônico. Ministério do Planejamento, Orçamento e Gestão, Secretaria de Logística e Tecnologia da Informação - Brasília: MP, SLTI, 2014. Disponível em: <https://bit.ly/2IWWFhy>. Acesso em: 27 ago. 2017.

BRITISH MUSEUM. Disponível em: <https://bit.ly/2nnaOrT>. Acesso em: 14 jan. 2018

ESPAÇO DO CONHECIMENTO UFMG. Disponível em: <https://bit.ly/2xb5OxE >. Acesso em: 13 jan. 2018

GOUVERNEMENT DU CANADA. Orientation sur la mise en œeuvre de la Norme sur l'accessibilité des sites Web. 2013. Disponível em: https://bit.ly/2KAEBNLl. Acesso em: 10 set. 2017

MEMORIAL MINAS GERAIS VALE. Disponível em: <https://bit.ly/2XsmFLe>. Acesso em: 8 jan. 2018

MOMA. Disponível em: <https://mo.ma/2RBf2gg>. Acesso em: 18 nov. 2017

MUSEU DE ARTES E OFÍCIOS. Belo Horizonte, 2013a. Disponível em: <https://bit. ly/2FywgG3>. Acesso em: 14 jan. 2018.

MUSEU DE ARTES E OFÍCIOS. Globo Horizonte realiza matéria sobre o Museu de Artes e Ofícios. Belo Horizonte, 2013b. Disponível em: <https://bit.ly/2FytZur>. Acesso em: 14 jan. 2018. 
MUSEU DA LÍNGUA PORTUGUESA. São Paulo, 2020. Disponível em: < https://bit. ly/2N9RJeG>. Acesso: 20 jan. 2018

MUSEU PICASSO. Madri, 2019. Disponível em: <https://bit.ly/1m4RgB0>. Acesso em: 20 jan. 2018.

OSORIO, Luiz Guilherme Brandão. Arte na internet: O Google Art Project. Disponível em: <https://bit.ly/2xdFHGh>. Acesso em: 10 jun. 2017.

QUEIROZ, Marco Antônio de. A Importância dos Padrões Web para a Acessibilidade de Sites. 2009. Acessibilidade Legal. Disponível em: <https://bit.ly/2LdJtYu>. Acesso em: 9 jan. 2017.

QUEIROZ, Marco Antônio de. Equivalentes Textuais para Acessibilidade de Imagens na Web. 2008. Acessibilidade Legal. Disponível em: <http://www.acessibilidadelegal.com/13equivalentes.php>. Acesso: 5 out. 2017.

TATE. Disponível em: <https://bit.ly/2KEuMhy>. Acesso em 19 jan. 2018

W3C. Diretrizes de Acessibilidade para Conteúdo Web (WCAG) 2.0. Traduzido Prof. Everaldo Bechara. 2008. Disponível em: <https://bit.ly/2aq4kCa>. Acesso em: 27 ago. 2017.

W3C. Understanding WCAG 2.0: A guide to understanding and implementing WCAG 2.0. 2016. Disponível: <https://bit.ly/1TQ79eI>. Acesso em: 27 ago. 2017.

W3C. How to Meet WCAG 2.0.2017. Disponível em: <https://bit.ly/2NcaYUU>. Acesso em: 27 ago. 2017.

Artigo apresentado em: 26/02/2019. Aprovado em 24/09/2019. 